\title{
Noise-Induced Hearing Loss (NIHL) as a Target of Oxidative Stress-Mediated Damage: Cochlear and Cortical Responses after an Increase in Antioxidant Defense
}

\author{
Anna Rita Fetoni, ${ }^{1 \star}$ Paola De Bartolo, ${ }^{3 \star}$ Sara Letizia Maria Eramo, ${ }^{2}$ Rolando Rolesi, ${ }^{1}$ Fabiola Paciello, ${ }^{1}$ \\ Christian Bergamini, ${ }^{4}$ Romana Fato, ${ }^{4}$ Gaetano Paludetti, ${ }^{1}$ Laura Petrosini, ${ }^{3}$ and Diana Troiani ${ }^{2}$ \\ Institutes of ${ }^{1}$ Otolaryngology and ${ }^{2}$ Human Physiology, Catholic University School of Medicine, I-00168 Rome, Italy, ${ }^{3}$ Department of Psychology, University \\ Sapienza of Rome and Institute for Inpatient Treatment and Scientific Studies, Santa Lucia Foundation, I-00185 Rome, Italy, and ${ }^{4}$ Department of \\ Biochemistry G. Moruzzi, University of Bologna, I-40126 Bologna, Italy
}

This study addresses the relationship between cochlear oxidative damage and auditory cortical injury in a rat model of repeated noise exposure. To test the effect of increased antioxidant defenses, a water-soluble coenzyme $Q_{10}$ analog $\left(Q_{\text {ter }}\right)$ was used. We analyzed auditory function, cochlear oxidative stress, morphological alterations in auditory cortices and cochlear structures, and levels of coenzymes $\mathrm{Q}_{9}$ and $\mathrm{Q}_{10}\left(\mathrm{CoQ}_{9}\right.$ and $\mathrm{CoQ}_{10}$, respectively) as indicators of endogenous antioxidant capability. We report three main results. First, hearing loss and damage in hair cells and spiral ganglion was determined by noise-induced oxidative stress. Second, the acoustic trauma altered dendritic morphology and decreased spine number of II-III and V-VI layer pyramidal neurons of auditory cortices. Third, the systemic administration of the water-soluble $\mathrm{CoQ}_{10}$ analog reduced oxidative-induced cochlear damage, hearing loss, and cortical dendritic injury. Furthermore, cochlear levels of $\mathrm{CoQ}_{9}$ and $\mathrm{CoQ}_{10}$ content increased. These findings indicate that antioxidant treatment restores auditory cortical neuronal morphology and hearing function by reducing the noise-induced redox imbalance in the cochlea and the deafferentation effects upstream the acoustic pathway.

\section{Introduction}

Noise exposure is one of the most common causes of hearing loss, and oxidative stress is central to current theories of noise-induced hearing loss (NIHL) (Henderson et al., 2006). There is growing evidence suggesting that NIHL can also induce homeostatic/maladaptive changes in the central auditory system (Syka, 2002; Pienkowski and Eggermont, 2011; Stolzberg et al., 2011; Wang et al., 2011). Most research has been focused on the analysis of plastic changes in the auditory cortex (AC) using electrophysiological techniques (Kotak et al., 2007; Scholl and Wehr, 2008; Pienkowski et al., 2011 and references within). However, noise effects can be correlated with specific structural changes within the CNS, and only a few authors have applied histological methods to analyze morphological changes in the central acoustic structures (Bose et al., 2010; Gröschel et al., 2010). In addition, little is presently known about the relationship between cochlear

Received May 11, 2012; revised Dec. 14, 2012; accepted Jan. 4, 2013.

Author contributions: A.R.F., P.D.B., L.P., and D.T. designed research; A.R.F., P.D.B., S.L.M.E., R.R., F.P., C.B., R.F., L.P., and D.T. performed research; A.R.F., P.D.B., S.L.M.E., R.R., F.P., C.B., R.F., G.P., L.P., and D.T. analyzed data; A.R.F., P.D.B., and D.T. wrote the paper.

This work was supported by university funds from Catholic University School of Medicine (UCSC). The confocal analysis has been performed at Labcemi, UCSC. We also thank Prof. Giorgio Lenaz for reading the manuscript and Dr. Giorgio Manini for technical assistance.

${ }^{*}$ A.R.F. and P.D.B. contributed equally to this work.

The authors declare no competing financial interests.

Correspondence should be addressed to Dr. Diana Troiani, Institute of Physiology, Catholic University School of Medicine, Largo F. Vito 1, I-00168 Rome, Italy. E-mail: d.troiani@rm.unicatt.it.

DOI:10.1523/JNEUROSCI.2282-12.2013

Copyright $\odot 2013$ the authors $\quad 0270-6474 / 13 / 334011-13 \$ 15.00 / 0$ noise damage and neuronal cortical injury. The present study addresses this issue in a rat model of repeated noise exposure.

We used immunohistochemical and histological techniques in conjunction with electrophysiology to relate cochlear injury to AC morphology. We also considered that interventions to attenuate NIHL are based on the application of antioxidant agents (Le Prell et al., 2007; Poirrier et al., 2010), and thus we used two approaches. First, to relate auditory cortical modifications to cochlear damage, we examined the morphological changes in the acoustic cortices (ACs), the hearing loss, the redox status in the cochlea, and the damage to hair cells (HCs) and spiral ganglion neurons (SGNs). Second, to test the hypothesis of impaired cochlear endogenous defenses as the causative element of NIHL, we analyzed whether an increase of the endogenous antioxidant defenses could ameliorate NIHL and the eventual cortical and cochlear damages. We selected the exogenous antioxidant coenzyme $\mathrm{Q}_{10}\left(\mathrm{CoQ}_{10}\right)$ analog because, in addition to its role in mitochondrial respiration and electron transport chain, CoQ acts as a potent antioxidant by either directly scavenging free radicals or recycling and regenerating other antioxidants (Bhagavan and Chopra, 2006; Lenaz et al., 2007). Furthermore, $\mathrm{CoQ}_{10}$ is known for its benefits in pathologies that exhibit impaired mitochondrial bioenergetic function and/or increased oxidative damage (Xu et al., 2010). In particular, we used a $\mathrm{CoQ}_{10}$ water-soluble formulation $\left(\mathrm{Q}_{\text {ter }}\right)$ because we demonstrated that it shows enhanced bioavailability with respect to the native form (Bergamini et al., 2012) and promotes outer hair cell (OHC) survival in a guinea pig NIHL model (Fetoni et al., 2009, 2012). 
The present research shows that modification of dendritic architecture in auditory pyramidal neurons is associated with noise-induced deafferentation and upward spread of cochlear damage. We also show that the systemic administration of a $\mathrm{CoQ}$ analog increases the cochlear defense system against oxidative stress and reduces both cortical and cochlear injuries.

\section{Materials and Methods}

Animals

Male adult Wistar rats (Catholic University School of Medicine) were used in this study (55-60 d, weighing 200-250 g at study onset). Four experimental groups comprised animals submitted to the following: (1) noise trauma only (group name, Noise; $n=79$ ); (2) noise trauma and antioxidant treatment (group name, Noise $Q_{\text {ter }} ; n=69$ ); (3) saline treatment only (group name, Ctrl; $n=40$ ); and (4) antioxidant treatment only (group name, $\mathrm{CtrlQ}_{\mathrm{ter}} ; n=53$ ). Throughout the experiment, animals were housed two per cage with temperature $\left(22-23^{\circ} \mathrm{C}\right)$ and humidity controlled ( $60 \pm 5 \%)$, under a $12 \mathrm{~h}$ light/dark cycle with food (4RF21; Mucedola) and water available ad libitum. All efforts were made to minimize animal suffering and to reduce the number needed for the experiments in accordance with the European Community Council Directive of November 24, 1986 (86/609/EEC). All procedures were performed in compliance with the Laboratory of Animal Care and Use Committee of the Catholic University, School of Medicine of Rome and were approved by the Italian Department of Health.

\section{Noise exposure}

The Noise and Noise $Q_{\text {ter }}$ groups $(n=148)$ were exposed to noise. The animals were placed in the anechoic room and exposed to a $100 \mathrm{~dB}$ sound pressure level (SPL) during 10 consecutive days ( $\mathrm{d} 0-10)$ for 60 min each day. The noise had a $10 \mathrm{kHz}$ center frequency. As described previously (Fetoni et al., 2009, 2010), the sound was generated by a waveform generator (LAG-120B, Audio Generator; Leader Electronics Corporation) and amplified by an audio amplifier (A-307R; Pioneer Electronics). The sound was presented in an open field by a dome tweeter (TW340X0; Audax) positioned at the center of the cage. Sound level was measured using a calibrated 1/4-inch microphone (model 7017; ACO Pacific) and a calibrated preamplifier (Acoustic Interface System; ACO Pacific).

\section{Drug treatment}

$\mathrm{Q}_{\text {ter, }}$, a soluble form of $\mathrm{CoQ}_{10}$ obtained by mechanophysical activation of $\mathrm{CoQ}_{10}$, is a terclatrate that brings different substances into supramolecular contact through the administration of energy, turning a simple mixture into a multicomposite material (proprietary technology by Asoltech). In the multicomposite $\mathrm{Q}_{\text {ter }}$, the $\mathrm{CoQ}_{10}$ is treated in association with a suitable carrier material and a bioactivator. $\mathrm{Q}_{\text {ter }}$ (provided by Scharper Therapeutics) is $\sim 200$ times more soluble and its antioxidant capacity is approximately five times greater than the native $\mathrm{CoQ}_{10}(\mathrm{Fe}-$ toni et al., 2009, 2012; Bergamini et al., 2012). $Q_{\text {ter }}$ is manufactured by using industrially available native $\mathrm{CoQ}_{10}$ (Kaneka Pharma Europe). In the $\mathrm{Q}_{\text {ter }}$ formulation, $\mathrm{CoQ}_{10}$ is present in only the oxidized form and embedded in a cage of cyclodextrines (an inactive pharmaceutical-grade excipient). The ingredients present in the $Q_{\text {ter }}$ formulation have no effect on cellular viability (Bergamini et al., 2012). $\mathrm{Q}_{\text {ter }}$ was dissolved in saline, and rats were given an intraperitoneal injection at a dose of $100 \mathrm{mg} / \mathrm{kg}$, corresponding to a final concentration of $10 \mathrm{mg} / \mathrm{kg} \mathrm{CoQ}{ }_{10}$. The dose of $100 \mathrm{mg} / \mathrm{kg}$ prevents the induction of oxidative stress by noise exposure in guinea pigs (Fetoni et al., 2009). The $\mathrm{Q}_{\mathrm{ter}}$ solution was prepared daily and administered to the animals of group $\mathrm{Noise}_{\text {ter }}$ beginning $3 \mathrm{~d}$ before the first traumatizing session and for the $10 \mathrm{~d}$ of noise exposure. The injection was given $1 \mathrm{~h}$ before the acoustic trauma sessions. The animals of group $\mathrm{CtrlQ}_{\text {ter }}$ received a similar drug treatment for a total of $13 \mathrm{~d}$ with no noise exposure. Each animal received a total of $1300 \mathrm{mg} / \mathrm{kg} \mathrm{Q}$ ter corresponding to $780 \mathrm{mg} / \mathrm{d} \mathrm{CoQ}_{10}$ in humans (Hidaka et al., 2008).

\section{Auditory brainstem response recordings}

Before auditory brainstem response (ABR) recordings, the animals were mildly anesthetized [ketamine at $10 \mathrm{mg} / \mathrm{kg}$ and medetomidine (Dormitor) at $10 \mathrm{mg} / \mathrm{kg}$ ] and placed in the anechoic room. Three stain- less steel recording electrodes were subcutaneously inserted posterior to the tested pinna (active), vertex (reference), and contralateral pinna (ground). ABRs were collected using a computer-controlled TDT System 3 (Tucker-Davis Technologies) data acquisition system with real-time digital signal processing. Tone bursts ranging from 6 to $32 \mathrm{kHz}$ (rise/fall time, $2 \mathrm{~ms}$; total duration, $2 \mathrm{~ms}$; repetition rate, 21/s) were presented monaurally in an open field using a horn tweeter (Tucker-Davis Technologies). The responses were filtered (100-3000 Hz bandpass), digitized, and averaged across 500 discrete samples at each frequency-level combination. ABRs were measured at low $(6 \mathrm{kHz})$, mid $(12,16$, and 20 $\mathrm{kHz}$ ), and high (24 and $32 \mathrm{kHz}$ ) frequencies. ABRs were assessed bilaterally in all animals $(n=241)$ before treatment and noise exposure to ensure normal hearing. ABRs were reassessed at several time points to evaluate the effect of repeated noise exposures on hearing. The time points included the following: (1) treatment onset $(\mathrm{d}-3)$; (2) before the first session of noise exposure ( $\mathrm{d} 0$ ); (3) before subsequent noise sessions $(\mathrm{d} 1,3,7)$; and (4) after the completion of the noise sessions (days 11, 30, and 60$)$.

The rat ABR is composed of four components (labeled from P1 to P4) occurring within $6 \mathrm{~ms}$ from stimulus onset (Church et al., 2012). These components reflect the neural activity chiefly from the auditory nerve (P1), the cochlear nucleus (P2), the superior olivary complex (P3), and the lateral lemniscus and/or inferior colliculus (P4). Thresholds were determined by decreasing tone intensity in $5 \mathrm{~dB}$ steps starting at $100 \mathrm{~dB}$ and decreasing to $0 \mathrm{~dB}$ or until a reliably scored $\mathrm{ABR}$ component was detected. Then, an ascending series of ABRs was gathered starting below this point and moving up in stimulus intensity (Fetoni et al., 2009, 2010). In rodents, the ABR P2 wave is the largest and usually the last wave to disappear as the sound stimulus decreases (Alvarado et al., 2012; Church et al., 2012). Hence, the threshold value was defined as the lowest intensity able to elicit the $\mathrm{P} 2$ wave. Threshold values, measured at day -3 and day 0 , were not significantly different at all tested frequencies in the different groups. Hearing loss was estimated by comparing ABR thresholds, recorded in the animals at day 0 (before the first session of acoustic trauma), with ABR thresholds at the different time points after the onset of noise exposure. Thus, the ABR data are expressed in terms of threshold and threshold shift that represents the difference between the pre-noise and post-noise exposure values of each animal for each group (Takemura et al., 2004). The neural transmission time for the cochlear nucleus was evaluated by studying the latency and amplitude of waveform P2. Latency-intensity (L-I) and amplitude-intensity (A-I) curves were derived (Boettcher et al., 1996; Alvarado et al., 2012). The latency of the ABR P2 component was defined as the time from the computer triggering of the earphone to the waveform positive peak, including a $0.3 \mathrm{~ms}$ acoustic transit time between the earphone and the animal pinnae. We selected the $20 \mathrm{kHz}$ frequency condition because it had the lowest ABR threshold and, therefore, provided the clearest L-I and A-I curves. An experimenter blind to treatment conditions scored the latencies and amplitudes of the ABR waves. Another experimenter then checked the ABR scoring for reliability.

\section{Oxidative damage analyses in the cochlea}

To assess the oxidative damage induced by repeated noise exposure, we used dihydroethidium (DHE) staining and 4-hydroxy-2-nonenal (4HNE) immunostaining at days 1 and 11. Noise exposure drives mitochondrial activity and unbalanced reactive oxygen species (ROS) production, including superoxide anion radicals and, in turn, lipid peroxidation and cell death (Ohinata et al., 2000; Yamashita et al., 2004). DHE and $4 \mathrm{HNE}$ provided indications on production of the toxic superoxide anion and oxidative degradation of lipids generated by the effect of free radicals, respectively. Each analysis was performed in 10 cochleae per group per time point (five animals per group per time point) for a total of 40 animals in each procedure. After the final ABR tests, animals were deeply anesthetized [ketamine at $20 \mathrm{mg} / \mathrm{kg}$ and medetomidine (Dormitor) at $20 \mathrm{mg} / \mathrm{kg}$ ] and transcardially perfused with $0.9 \% \mathrm{NaCl}$ (room temperature). The cochleae were quickly removed, and the samples were fixed with $4 \%$ paraformaldehyde in $\mathrm{PBS}$ at $4^{\circ} \mathrm{C}$ and a $\mathrm{pH}$ 7.5. Next, the cochleae were decalcified for $15 \mathrm{~d}$ in EDTA (10\% EDTA, changed daily), 
incubated for $48 \mathrm{~h}$ in sucrose (30\%), embedded in OCT, and cryosectioned at a thickness of $12 \mu \mathrm{m}$ (Cryostat CM 1950; Leica).

\section{DHE staining}

DHE is a lipophilic cell-permeable dye that is rapidly oxidized to ethidium in the presence of free radical superoxide. The produced ethidium is fixed by intercalation into nDNA, thus giving an indication of oxidant stress within cells. The cochlear specimens were incubated with $1 \mu \mathrm{M}$ DHE (Invitrogen) in PBS for $30 \mathrm{~min}$ at $37^{\circ} \mathrm{C}$ and then coverslipped with an antifade medium (ProLong Gold; Invitrogen). Fluorescent images were obtained with a confocal laser microscope (TCS-SP2; Leica Microsystems). The staining was imaged by two-photon excitation (792 nm, <140 fs, $90 \mathrm{MHz}$ ) performed by an ultrafast tunable modelocked titanium:sapphire laser (Chameleon; Coherent). Images were taken at $20 \times$.

\section{HNE immunostaining}

Lipid peroxidation is readily initiated by hydroxyl radicals, and a single initiating reaction can generate multiple peroxide radicals via a chain reaction. The $\alpha, \beta$-unsaturated hydroxyalkenal $4 \mathrm{HNE}$ is a byproduct of lipid peroxidation in cells. As described previously (Fetoni et al., 2010), the slides were incubated in a blocking solution containing $1 \%$ fatty acid-free bovine serum albumin (BSA), 0.5\% Triton X-100, and 10\% mouse serum in PBS for $1 \mathrm{~h}$ at room temperature. The specimens were then incubated overnight at $4^{\circ} \mathrm{C}$ with a solution containing mouse monoclonal anti-4HNE primary antibody (Oxis International) diluted 1:100 in PBS. The mouse anti-4HNE antibody crossreacted with the rat tissue. At the end of the incubation, all slides were washed twice in PBS and incubated at room temperature for $2 \mathrm{~h}$, light-protected, in labeled conjugated goat anti-mouse secondary antibody (Alexa Fluor 488, IgG; Invitrogen) diluted 1:400 in 0.1 M PBS. After another wash in PBS, samples were double stained with DAPI (blue fluorescence, 1:500) for $15 \mathrm{~min}$ in the dark at room temperature. DAPI labeling was used to identify condensed cell nuclei. The slides were coverslipped with an antifade medium (ProLong Gold; Invitrogen). Images of 4HNE immunolabeled specimens $(20 \times)$ were taken by a confocal laser scanning microscope (Leica Microsystems) equipped with an argon/argon-krypton laser and a helium/neon laser for 488 and 519 excitation. DAPI staining was imaged by two-photon excitation $(740 \mathrm{~nm},<140 \mathrm{fs}$, $90 \mathrm{MHz}$ ) performed by an ultrafast tunable mode-locked titanium:sapphire laser. $4 \mathrm{HNE}-$ positive cells were identified by green fluorescence. Control experiments were performed by omitting the primary antibody during processing of tissue randomly selected across experimental groups. Staining was absent in the HCs and SGNs, indicating neither spontaneous fluorescence nor nonspecificity of antibody. Tissues from all groups were always processed together during the procedures to limit variability related to antibody penetration, incubation time, post-sectioning age, and condition of tissue.

\section{Western blot analyses}

Western blot was performed to confirm immunohistochemistry data and to produce semiquantitative data on the marker of lipid peroxidation, $4 \mathrm{HNE}$. The analysis was performed in a total of 45 animals (five animals per group). The groups included Ctrl, $\mathrm{Ctrl}_{\mathrm{ter}}$ day $1, \mathrm{Ctrl}_{\mathrm{ter}}$ day 11, Noise day 1, Noise day 3, Noise day 11, Noise day 60, NoiseQ ter day 1, and $N_{\text {Noise }} Q_{\text {ter }}$ day 11 . After the final ABR recording, the animals were killed as described above. The cochleae were quickly removed from the skull, the tympanic bulla was exposed, and the bony capsule of the cochlea and the lateral wall tissues were removed under stereomicroscope. The specimens from each group included the modiolus and the organ of Corti. They were collected on ice, stored at $-80^{\circ} \mathrm{C}$, homogenized using a RIPA buffer [ $50 \mathrm{~mm}$ Tris/HCl, $150 \mathrm{~mm} \mathrm{NaCl}, 1 \%$ SDS, $1 \%$ Triton X-100, 1\% of a mixture of inhibitors ( 1 mM PMSF, 2 mM leupeptin, $1.5 \mathrm{~mm}$ pepstatin $\mathrm{A}, 80 \mathrm{~mm}$ aprotinin, 4 mм pepstatin, $1.4 \mathrm{~mm} \mathrm{E}-64$, $104 \mathrm{~mm}$ 4-(2-aminoethyl)benzenesulfonyl fluoride, $1 \mathrm{~mm}$ EDTA, $0.2 \mathrm{~mm}$ $\mathrm{Na}_{3} \mathrm{VO}_{4}$, and $0.1 \mathrm{~mm} \mathrm{NaF}$ )]. After centrifugation for $15 \mathrm{~min}$ at 12,000 $\mathrm{rpm}$ at $4^{\circ} \mathrm{C}$, the supernatants were collected, and the protein concentration was measured using a Micro BCA kit (Pierce). For each sample, 100 $\mu \mathrm{g}$ of protein was separated by SDS-PAGE on a $10 \%$ gel. Proteins were then transferred onto nitrocellulose membranes using a solution con- taining $50 \mathrm{~mm}$ Tris/ $\mathrm{HCl}, 380 \mathrm{~mm}$ glycine, and 20\% methanol overnight at $4^{\circ} \mathrm{C}$ and then stained with Ponceau $\mathrm{S}$ to ensure protein transfer (ICN Biochemicals). Nonspecific binding sites were blocked with $5 \%$ dry milk in Tris-buffered saline (TTBS; $20 \mathrm{~mm}$ Tris, $500 \mathrm{~mm} \mathrm{NaCl}$, and $0.05 \%$ Tween 20). Next, the membranes were incubated overnight at $4^{\circ} \mathrm{C}$ with the primary antibody (HNE, 1:2500; Abnova) diluted in 3\% BSA and $0.05 \% \mathrm{NaN}_{3} /$ TTBS. After five rinses in buffer, membranes were incubated for $1 \mathrm{~h}$ at room temperature with a horseradish peroxidaseconjugated anti-rabbit IgG secondary antibody (Promega) that was diluted 1:2500 in 2.5\% dry milk/TTBS. Blots were developed using enhanced chemiluminescence reagents (ECL; GE Healthcare). The immunoreacted bands were visualized by exposing membranes to Kodak $\mathrm{X}$-OMAT films. Equal protein loading among individual lanes was confirmed by reprobing the membranes with an anti- $\alpha$-actin mouse monoclonal antibody at a 1:1000 dilution (Thermo Fisher Scientific). This anti-mouse antibody crossreacted with the rat tissue. The obtained films were evaluated for densitometry by means of an optical computed system (Epson Perfection, 1240U Photo). All values were normalized to the control group. The experiments were repeated three times, and an interexperiment variability of $<10 \%$ was found.

\section{Morphological analyses in the cochlea and acoustic cortex}

The rhodamine-phalloidin ( $\mathrm{Rh}-\mathrm{Ph}$ ) staining, Nissl staining, and GolgiCox techniques were performed at day 60 to quantitatively assess HCs integrity, SGN viability, and AC morphology, respectively. After the last $A B R$ recording $(\mathrm{d} 60)$, the animals were killed, and the cochleae and the brains were quickly removed. A total of 44 animals were used (Ctrl, $n=$ 9; $\mathrm{CtrlQ}_{\text {ter }}, n=9$; Noise, $n=13$; Noise $\mathrm{Q}_{\text {ter }}, n=13$ ): the right cochleae were processed for $\mathrm{Rh}-\mathrm{Ph}$ analysis, the left cochleae for the Nissl staining, and the brains for cortical analyses.

$\mathrm{Rh}-\mathrm{Ph}$ staining. $\mathrm{Rh}-\mathrm{Ph}$ is a high-affinity $\mathrm{F}$-actin probe conjugated to the red-orange fluorescent dye tetramethylrhodamine (TRITC). This stain is used to visualize the stereociliary arrays and cuticular plate of HCs. Surface preparations of the basilar membrane with the organ of Corti were processed. Briefly, the removed right cochleae were fixed with $10 \%$ buffered Formalin for $4 \mathrm{~h}$. After removal of the bony capsule and the lateral wall tissues, the epithelium of the organ of Corti was separated from the bony modiolus and dissected in half-turns in $0.1 \mathrm{~m}$ PBS under a dissecting microscope. To visualize HCs and their stereocilia, the specimens were incubated with a solution containing $0.5 \%$ Triton X-100 and stained for F-actin with rhodamine-conjugated phalloidin (1:100 dilution; Invitrogen) for $1 \mathrm{~h}$ at room temperature protected from light. At the end of the incubation, all specimens were washed twice in PBS. Afterward, the stained specimens were mounted on slides containing an antifade medium as described above. Quantification of HC survival was performed with the aid of Leica Microsystems confocal microscope using filters with an excitation of $516 \mathrm{~nm}$ and an emission of $543 \mathrm{~nm}$. Z-stack series of 3-5 $\mu \mathrm{m}$ thickness were acquired as images of $1023 \times 1023$ pixels recorded at intervals of $0.5 \mu \mathrm{m}$ (Fetoni et al., 2010). Images were taken at $40 \times$ and $100 \times$. Positive cells were counted in segments of $\sim 250 \mu \mathrm{m}$ in length each along the basilar membrane. The criterion to assess HC loss was either a dark spot and/or the typical phalangeal scar of supporting cells in the spaces previously filled by OHCs (Hu and Henderson 1997; Minami et al., 2007). The results are expressed as percentage of remaining HCs over the entire length of the basilar membrane (Viberg and Canlon, 2004).

Nissl staining. Sections of the left cochleae $(12 \mu \mathrm{m})$ were made with a cryostat and mounted onto slides. The sections were stained with cresyl violet $(0.1 \%$ for $5 \mathrm{~min})$ for the histological assessment of ganglion neuronal cell damage, which is dependent on viable and nonviable stained cells. SGN densities for each of the three cochlear turns (basal, middle, and apical) were measured from five representative mid-modiolar sections. Each cochlear turn was identified, and the cross-sectional area of Rosenthal's canal within each turn was measured using NIH Image. Viable neurons with a clear round nucleus and homogeneous cytoplasm were then counted in each turn. The SGN density (cells per square millimeters) was calculated using NIH Image $1.43 \mathrm{u}$ (Image Processing and Analysis in Java) in a $500 \times 500 \mu \mathrm{m}$ area. The mean number of stained cells was obtained by three researchers blinded to the experimental con- 
ditions. The cell viability from each group is presented as number of cells per square millimeters.

Golgi-Cox staining technique. To evaluate the morphological features of the AC pyramidal neurons, five brains per group were removed and impregnated by using a Golgi-Cox solution (Glaser and Van der Loos, 1981). Briefly, brains were immersed in a solution performed with $5 \%$ $\mathrm{Cr}_{2} \mathrm{~K}_{2} \mathrm{O}_{7}, 5 \% \mathrm{Cl}_{2} \mathrm{Hg}$, and $5 \% \mathrm{CrK}_{2} \mathrm{O}_{4}$ (Sigma-Aldrich) in distilled water for $15 \mathrm{~d}$, transferred to a $30 \%$ sucrose solution for 3-5 d, and then sectioned in $200 \mu \mathrm{m}$ coronal sections at the level of primary and secondary acoustic cortices from -3.30 to $-4.80 \mathrm{~mm}$ in relation to bregma (Paxinos and Watson, 2007) using a vibratome. The sections were mounted on gelatinized slides and stained according to the method described by Gibb and Kolb (1998). Slides were rinsed in distilled water for $1 \mathrm{~min}$, placed in $\mathrm{H}_{5} \mathrm{NO}$ (Sigma-Aldrich) for $30 \mathrm{~min}$ in the dark, rinsed in distilled water for $1 \mathrm{~min}$, placed in Kodak Fix (Sigma-Aldrich) for film for $30 \mathrm{~min}$ in the dark, rinsed in distilled water for $1 \mathrm{~min}$, placed sequentially in 50,70 , and $95 \%$ alcohol for $1 \mathrm{~min}$, twice in $100 \%$ alcohol for $5 \mathrm{~min}$, in a solution of one-third chloroform, one-third xylene, and one-third $100 \%$ alcohol for $15 \mathrm{~min}$, and then placed in xylene for $15 \mathrm{~min}$. Finally, sections were coverslipped with Canada Balsam.

The stained sections were analyzed using a light microscope (Axioskop; Carl Zeiss) with a $100 \times$ oil-immersion objective lens. Cortical pyramidal neurons were identified by the presence of a basal dendritic tree, distinct single apical dendrite, and dendritic spines. A researcher unaware of the identity of the specimen performed morphological analyses using the Neurolucida (MicroBrightField) software for reconstructing dendritic arbors.

Neurons were selected only if the labeling was uniform and lacked any reaction precipitate, they were relatively isolated from neighboring impregnated neurons to avoid overlapping, the predominant plane of the dendritic arbors was parallel to the plane of the section, the dendritic arborizations were intact and visible as far as the most distal branches of apical and basal dendrites, and spines were clearly marked (Gelfo et al., 2009). According to these criteria, 160 pyramidal neurons (20 per group for a total of 80 in layer II-III and 80 in layer V-VI) belonging to primary and secondary ACs were selected. In each neuron, apical and basal dendritic trees were separately examined by Sholl Analysis (Sholl, 1956). This procedure is based on virtually including the whole neuron in a set of concentric shells at $10 \mu \mathrm{m}$ intervals centered on the cell body.

The parameters analyzed included the following: (1) dendritic length (in micrometers), calculated by summing the length of all processes passing through each shell; (2) dendritic nodes, calculated by summing all points from which dendritic branches arose; (3) terminal spine density, calculated by measuring the length of dendritic terminal of $\sim 25 \mu \mathrm{m}$ and counting the number of spines (i.e., the protrusions of the dendritic membrane regardless of their shape or actual function) along the segment (spine density/1 $\mu \mathrm{m}$ ); (4) total spine density, calculated as the total number of spines divided by the number of concentric shells at $10 \mu \mathrm{m}$ intervals (only the first $10 \mu \mathrm{m}$ of the arborization were excluded because of their lack of spines, (DeFelipe and Fariñas, 1992); and (5) spine distribution, distinguished in maximal spine concentration (i.e., maximal spine density $/ 10 \mu \mathrm{m}$ ) and its distance from soma.

\section{Extraction and quantification of $\mathrm{CoQ}$}

To evaluate the cellular uptake/distribution of $\mathrm{Q}_{\text {ter }}$, we analyzed the amount of CoQ in the cochleae and ACs. We distinguished between $\mathrm{CoQ}_{9}$ and $\mathrm{CoQ}_{10}$ considering that the predominant forms of CoQ are $\mathrm{CoQ}_{10}$ in humans and the homolog $\mathrm{CoQ}_{9}$ in rodents. Extraction of total CoQ was performed as described previously (Takada et al., 1984; Bergamini et al., 2012) from 70 animals at days 1, 11, and 60 (Ctrl, $n=6$; $\mathrm{CtrlQ}_{\mathrm{ter}}, n=12$; Noise, $n=26$; NoiseQ $\mathrm{ter}_{\text {, }}, n=26$ ). Quantification of CoQ was performed by HPLC analysis. Briefly, the tissues were homogenized in 200-400 $\mu \mathrm{l}$ of PBS by means of an Ultra-Turrax apparatus, and then $7 \mathrm{vol}$ of extraction solution (hexane/ethanol, 5:2 v/v) were added and vigorously mixed for $5 \mathrm{~min}$ using a vortex. The mixture was centrifuged for $3 \mathrm{~min}$ at $4000 \mathrm{rpm}$, and the hexane layer was collected. The extraction procedure was repeated twice, and then the collected hexane layers were dried under a stream of nitrogen and dissolved in 50-100 $\mu \mathrm{l}$ of ethanol. The HPLC system consisted of a Waters 510 HPLC pump, variable volume injector (U6K; Waters), a Kinetex reverse-phase C18 column $(100 \times 4.6 \mathrm{~mm}, 2.6 \mu \mathrm{m}$; Phenomenex $)$, and a photodiode array detector (996; Waters). The ethanolic extracts were eluted isocratically using a mobile phase consisting of ethanol/water $(97: 3 \mathrm{v} / \mathrm{v})$ at a flow rate of $0.6 \mathrm{ml} / \mathrm{min}$. The identity of $\mathrm{CoQ}_{9}$ and $\mathrm{CoQ}_{10}$ peaks was confirmed by coelution with standards. The quantification, reported as picomoles per milligrams of CoQ normalized to tissue wet weight, was obtained by comparing peak areas and standard solutions (Sigma-Aldrich) at a wavelength of $275 \mathrm{~nm}$. In the $\mathrm{Q}_{\text {ter }}$ formulation, $\mathrm{CoQ}_{10}$ is present only in the oxidized form, and our CoQ extraction conditions induce the complete oxidation of the quinones (Bergamini et al., 2012). Thus, all reported data refer to the total amount of oxidized quinones.

\section{Statistical analyses}

The results are presented as means \pm SEM. Differences were assessed by using ANOVAs. Namely, ABR data were analyzed by means of three-way ANOVA (group $\times$ day $\times$ frequency; group was considered a betweensubject factor, whereas frequency and day were within-subject factors). Latency and amplitude data were analyzed by means of two-way ANOVAs (group $\times$ decibels; group was the between-subject factor, whereas decibels was the within-subject factor). Cochleogram data were analyzed by means of a two-way ANOVA (group $\times$ location along the entire basilar membrane; group was the between-subject factor, whereas location was the within-subject factor). Western blot data were analyzed by means of a one-way ANOVA. Cortical neuronal data and $\mathrm{CoQ}_{9}$ and $\mathrm{CoQ}_{10}$ quantification data were analyzed by means of two-way ANOVAs (noise exposure and drug treatment as between-subject factors). Post hoc comparisons were assessed with Tukey's tests (Statistica; Statsoft). Values of $p<0.05$ were considered significant.

\section{Results}

\section{Repeated noise exposure causes hearing loss and cochlear oxidative imbalance: the cochlear injury is reduced by antioxidant treatment}

\section{Hearing loss}

The hearing loss was evaluated by ABR threshold measurements. Before noise exposure, mean ABR thresholds ranged from 20 to $35 \mathrm{~dB}$ SPL across frequency with the lowest threshold at $20 \mathrm{kHz}$ (Fig. 1A). The administration of $\mathrm{Q}_{\text {ter }}$ or vehicle saline in the $\mathrm{CtrlQ}_{\text {ter }}$ and Ctrl groups, respectively, did not alter $\mathrm{ABR}$ values. In the noise-exposed animals (Noise group; Fig. 1A), ABR thresholds were elevated at the beginning of noise exposure (d 1) and progressively increased until day 11 . At days 30 and 60, there was no additional increase with respect to day 11 . Similarly to previous reports (Mills et al., 1981; Wang and Ren, 2012), threshold shift pattern worsened with repeated noise exposure, reaching a permanent threshold shift value. The noise-exposed animals had significant ABR threshold shifts (Noise group; Fig. 1B) after the first noise exposure session $(\sim 10 \mathrm{~dB}$ at $\mathrm{d} 1)$ that progressed with

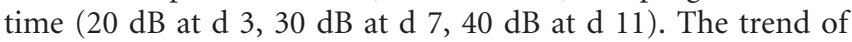
threshold shift increase was analogous across mid and high frequencies. At days 30 and 60, there was no significant increase with respect to day 11 (group Noise; Fig. 1B). Repeated noise exposure induced threshold shift for all frequencies tested with a peak between 16 and $24 \mathrm{kHz}$.

$\mathrm{Q}_{\text {ter }}$ treatment significantly attenuated the elevation of the hearing threshold (Fig. 1 C): there was an $\sim 60 \%$ amelioration of threshold values in the NoiseQ $Q_{\text {ter }}$ group compared with the Noise group. Figure $1 C$ shows that this improvement was observed as early as day 11 ( $1 \mathrm{~d}$ after the end of treatment). When compared with the Noise group, the Noise $Q_{\text {ter }}$ group exhibited a decrease of the threshold shift by 25-30 dB for mid and high frequencies and by $15 \mathrm{~dB}$ for the low frequency (Fig. 1D). The values of threshold shift at day 11 ( $\sim 15 \mathrm{~dB}$ for mid and high frequencies; $5 \mathrm{~dB}$ for low frequency) represented the permanent hearing loss in the 

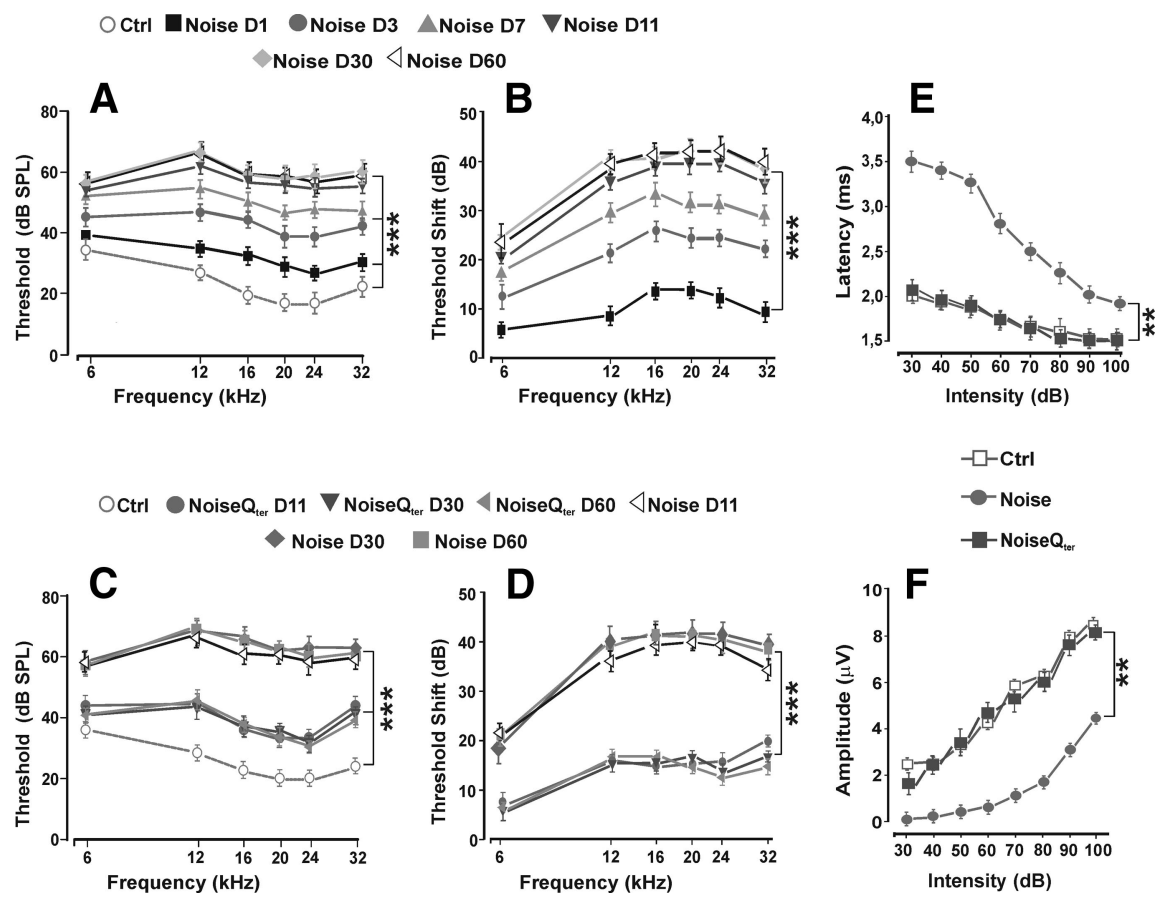

Figure 1. NIHL is ameliorated by $Q_{\text {ter }}$ treatment. The effect of noise on the auditory function $(A, B)$ and the protective effect of $Q_{\text {ter }}(\boldsymbol{C}, \boldsymbol{D})$ at the different time points from noise exposure. ABR averaged threshold $(\boldsymbol{A}, \boldsymbol{C})$ and threshold shift $(\boldsymbol{B}, \boldsymbol{D})$ values $( \pm S E M)$ measured in Ctrl, Noise, and Noise $Q_{\text {ter }}$ groups. In the Noise group, threshold progressively increases during noise exposure sessions $\left(A, C\right.$, and no recover of threshold shift value is observed at days 30 and $60(B, D)$. In the Noise $Q_{\text {ter }}$ group, the threshold elevation is $\sim 10-15 \mathrm{~dB}$ with respect to the $\mathrm{Ctrl}$ group at the end of noise sessions $(C) .{ }^{* * *} p<0.0001$, post hoc comparisons between groups in the presence of significant interactions between group and day factors from three-way ANOVAs. L-I and A-I curves of the P2 waveform ( $20 \mathrm{kHz}$, day 11 ) are shown in $\boldsymbol{E}$ and $\boldsymbol{F}$, respectively. In the Noise group, the $P 2$ wave is significantly increased in latency and decreases in amplitude, and their values return to control values in the $\mathrm{Noise}_{\text {ter }}$ group. ${ }^{* *} p<0.001$, post hoc comparison from two-way ANOVA.
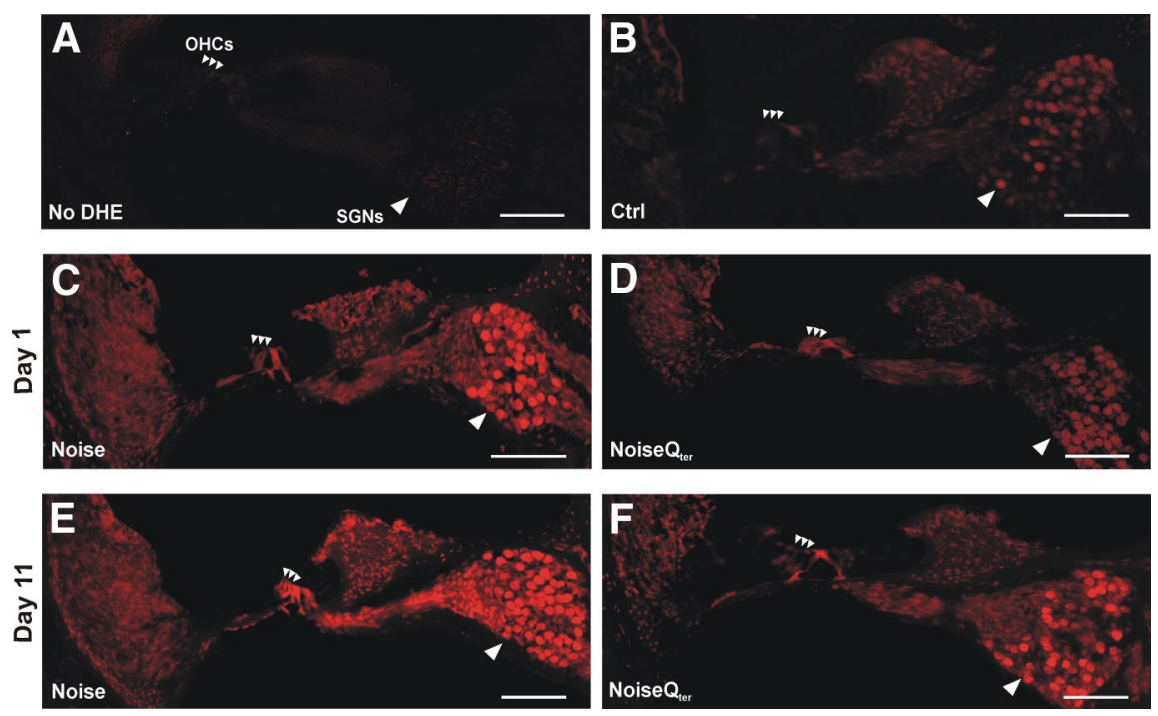

Figure 2. Noise-induced superoxide production is reduced by $Q_{\text {ter }}$ treatment. DHE-positive OHCs and SGNs are shown by arrowheads. Spontaneous fluorescence is absent in cochlear tissues $(\boldsymbol{A})$. The fluorescence is faint in the Ctrl group $(\boldsymbol{B})$, progressively increases in the Noise group $(\boldsymbol{C}, \boldsymbol{E})$, and decreases in the $\mathrm{Noise}_{\text {ter }}$ group $(\boldsymbol{D}, \boldsymbol{F})$ at days 1 and 11 . Scale bar, $100 \mu \mathrm{m}$.

Noise $Q_{\text {ter }}$ group because there was no additional improvement at day 30 or 60 .

The neural transmission times to the cochlear nucleus were evaluated by studying the latency and amplitude of waveform P2 for $20 \mathrm{kHz}$ at day 11. In the Noise group, the P2 wave was significantly increased in latency (Fig. 1E) and decreased in amplitude
(Fig. $1 F$ ). These findings suggested impairment of neural synchrony and/or number of neural unit firing. On the contrary, P2 wave latency and amplitude returned to control values in the Noise $Q_{\text {ter }}$ group (Fig. 1E,F), indicating a decrease of the impairment.

\section{Oxidative damage}

Figures 2 and 3 illustrate the oxidative damage in HCs and SGNs after noise exposure at days 1 and 11 using the superoxide and lipid peroxidation markers.

As shown in Figure 2B, DHE staining was faint in the unexposed cochleae. In noise-exposed rats (Fig. 2C-E), the fluorescence was intense in HCs and SGNs of the most severely damaged medial-basal part of the cochlea. The fluorescence increased from day 1 (Fig. 2C) to day 11 (Fig. 2E). Noise exposure effects were counteracted by $\mathrm{Q}_{\text {ter }}$ administration: $\mathrm{HCs}$ and SGNs of NoiseQ ter $_{\text {animals exhibited }}$ a faint DHE fluorescence at days 1 (Fig. 2D) and 11 (Fig. 2F).

Similarly to DHE, 4HNE immunostaining (Fig. 3B) showed a faint fluorescence in the control cochleae. In noise-exposed rats (Fig. 3C-E), the fluorescence was increased in HCs and SGNs of the most severely damaged medial-basal part of the cochlea. $4 \mathrm{HNE}$ fluorescence increased from day 1 (Fig. 3C) to day 11 (Fig. 3E), and noise exposure effects were counteracted by $Q_{\text {ter }}$ administration (Fig. 3D-F).

Western blot analysis (Fig. 4) confirmed the $4 \mathrm{HNE}$ immunofluorescence data. An increased level of $4 \mathrm{HNE}$ expression was observed at days 1,3 , and 11; the expression significantly decreased at day 60 , reaching the level found at day 1 (Fig. $4 A$ ). The blotting analyses indicated that $\mathrm{Q}_{\text {ter }}$ treatment (Fig. $4 B$ ) prevented the initial expression of $4 \mathrm{HNE}$ at day 1 and significantly reduced the immunoreactivity at the end of treatment (d 11).

\section{HC and SGN viability}

The quantitative assessment of HC survival was determined by $\mathrm{Rh}-\mathrm{Ph}$ staining of HC apical pole (Fig. 5). The SGN viability was evaluated by Nissl staining (Fig. 6). These assays were performed at day 60 after noise exposure.

In $\mathrm{Rh}-\mathrm{Ph}$ images, three rows of $\mathrm{OHCs}$ and one row of inner hair cells (IHCs) were seen in images at low magnification. However, because OHCs and IHCs are located at different optical planes, it was difficult to get a focused image of both OHCs and IHCs. Therefore, in this study, we mainly examined the region of OHCs. In the noise-unexposed animals, OHC surfaces were characterized by an orderly arrangement of the stereocilia and cuticular plates (Fig. 5A). In the Noise 
group, marked OHC loss and slight IHC disappearance were observed (Fig. 5B). $\mathrm{OHC}$ loss was pronounced in the region of the cochlear middle turn, less evident in the basal turn, and completely absent in the apical one (quantification is shown in Fig. $5 G$ ). OHC loss was characterized by dark spots, phalangeal scars (Fig. $5 B$ ), and disappearance of both cuticular plate and hair bundle. Furthermore, a disorganization of OHC hair bundle, characterized by disruption of the $\mathrm{V}$ shape and misorientation (Fig. $5 D-F$ ), were observed mostly in the middle turn and, with a decreasing pattern, in the basal turn. In the NoiseQ ${ }_{\text {ter }}$ group, $\mathrm{OHC}$ loss was significantly reduced and the hair bundle arrangement was primarily restored in the middle and basal turns (Fig. 5C,F and cochleogram of $G$ ).

Figure 6 shows the Nissl histology of the spiral ganglion. In Ctrl group, the Rosenthal's canal was densely packed with SGNs and fascicles of auditory nerve fibers (Fig. 6A). The SGN number was reduced at day 60 , and the most extensive reductions in SGN density occurred mainly in the middle turn and moderately in the basal turn (Fig. 6B). Similarly to OHCs, $\mathrm{Q}_{\text {ter }}$ administration increased the number of preserved SGNs and soma appeared normal (Fig. 6C). SGN loss, quantified by SGN count, is shown in Figure $6 D$.

\section{Cortical morphological modifications} are related to noise-induced cochlear injury and are affected by antioxidant treatment

Repeated noise exposure causes modifications in auditory cortical pyramidal neurons

Pyramidal neurons belonging to layers IIIII and V-VI of ACs were analyzed by using the Golgi-Cox technique from tissue collected at day 60 (see Figs. $7 A, 8 B, 9 B$ ). In both layers, the acoustic trauma significantly increased the neuronal length both in apical and basal dendrites; however, it did not affect dendritic nodes in both arborizations (Fig. 7B,C). The acoustic trauma significantly decreased both terminal and total spine densities in the apical and basal dendrites of both layers (Figs. 8A, $9 A)$. The analysis of spine distribution revealed that the maximal spine concentration significantly decreased in both apical and basal dendrites of both layers as a consequence of acoustic trauma (Figs. 8A, 9A). The distance from the soma of maximal spine concentration remained unaltered in both arborizations of layer II-III (Fig. 8A), whereas it was distally shifted in apical and basal dendrites of layer V-VI (Fig. 9A), reducing the efficacy of synapses on neuronal output.

Antioxidant treatment layer selectively ameliorates the cortical neuronal injury

Morphological analyses of the ACs revealed that $\mathrm{Q}_{\text {ter }}$ treatment did not modify the dendritic length enhanced by the
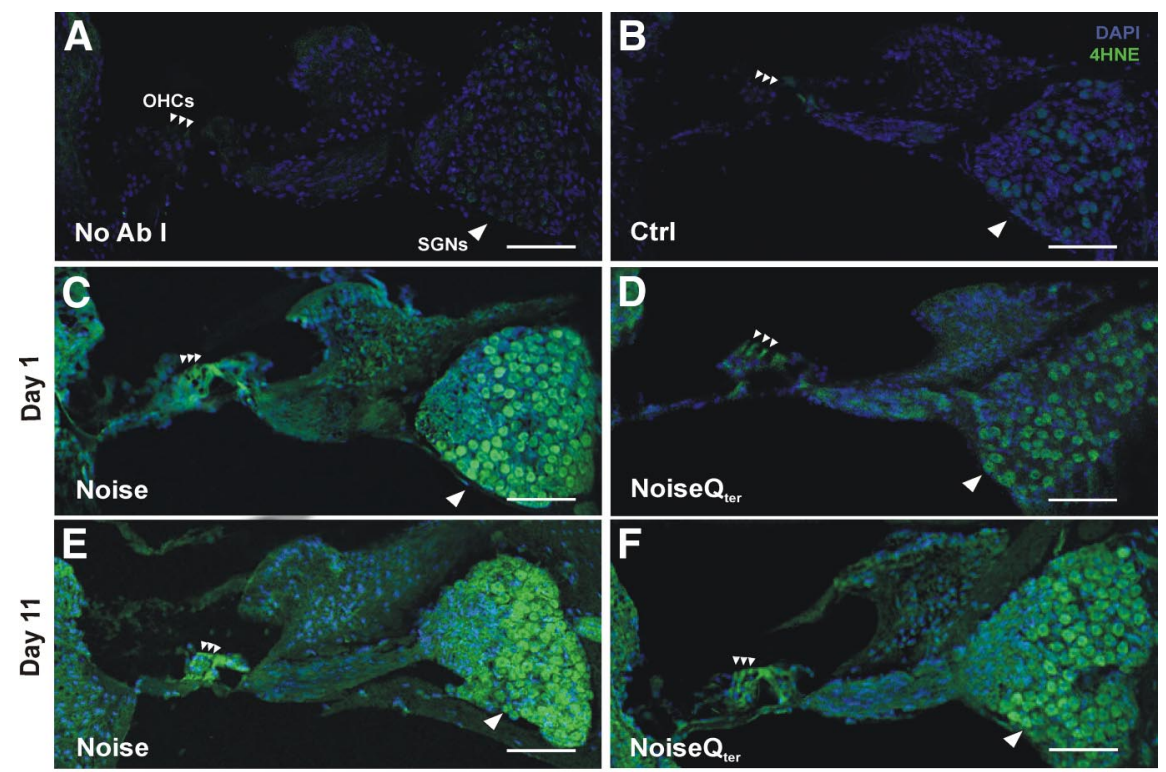

Figure 3. Noise-induced lipid peroxidation in HCs and SGNs is reduced by $Q_{\text {ter }}$ treatment. 4HNE-positive OHCS and SGNs are shown by arrowheads. Staining is absent in negative control specimen $(\boldsymbol{A})$, indicating neither spontaneous fluorescence nor nonspecificity of the secondary antibody. The fluorescence is faint in the $\operatorname{Ctrl}$ group $(\boldsymbol{B})$, increases in the Noise group $(\boldsymbol{C}, \boldsymbol{E})$, and

Figure 4. Western blot analysis for 4HNE expression in the cochlea. $\boldsymbol{A}$, Noise effect on lipid peroxidation is still present at day 60 in the Noise group. $\boldsymbol{B}, Q_{\text {ter }}$ reduces lipid peroxidation during the noise sessions by decreasing the oxidative unbalance. Histograms represent densitometry evaluations. ${ }^{* *} p>0.001,{ }^{* * *} p>0.0001$.
B
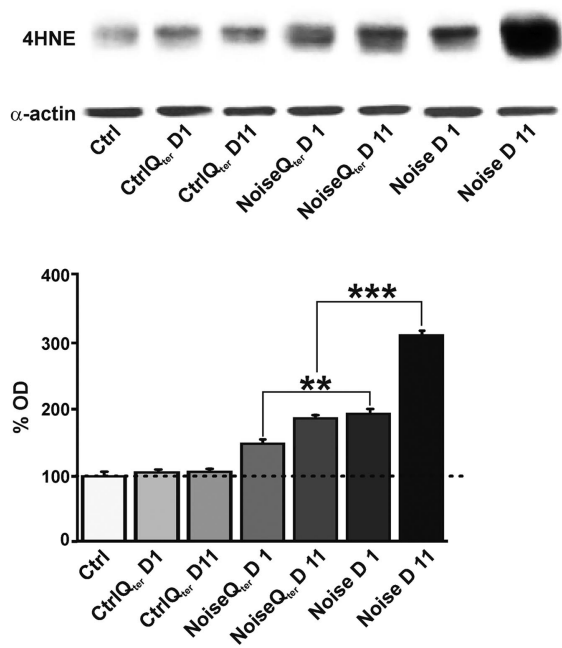

acoustic trauma in the apical and basal arborizations of layer II-III and V-VI pyramidal neurons (Fig. 7B). The treatment did not affect the dendritic nodes of both layers (Fig. 7C). However, in regards to terminal and total spine densities for both apical and basal dendrites, $Q_{\text {ter }}$ treatment rescued control values in layer II-III (Fig. 8) but not layer V-VI (Fig. 9). In accordance, the maximal spine density was restored to control values without modifying its distance from soma in layer II-III (Fig. 8A). On the contrary, in layer V-VI, Q treatment did not reestablish the maximal spine density that was decreased as a consequence of the acoustic trauma. The treatment also did not restore the distance from the soma, which was distally shifted as a consequence of the acoustic trauma (Fig. 9A). 

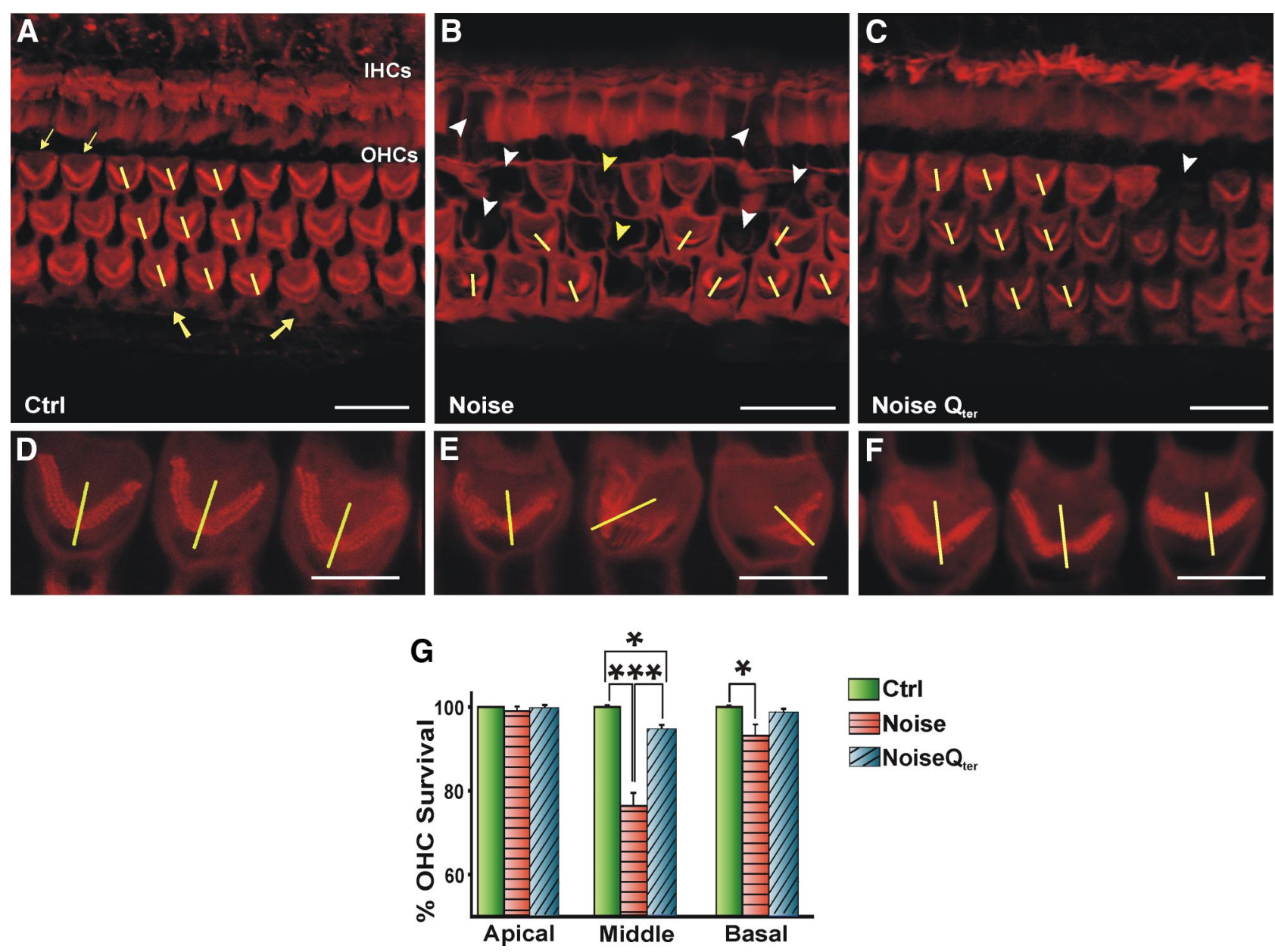

Figure 5. Surface preparation images showing the distribution of F-actin in the middle turn region of the organ of Corti. $A$, The normal cochlea organization (Ctr) is represented: IHC single row and $\mathrm{OHC}$ three rows are well aligned, the cuticular plate is indicated by slim arrows, the orderly hair bundle arrangement by yellow lines, and the phalangeal processes of Deiters' cells, which are weakly stained, by arrows. In $\boldsymbol{B}$, white arrowheads indicate missing $\mathrm{OHCs}$ and IHCS (dark spots), yellow lines the misorientation of hair bundles, and yellow arrowheads the phalangeal scars. In $\boldsymbol{C}$, the $\mathrm{HC}$ loss is reduced by $Q_{\text {ter }}$ treatment. Only few cells disappear and the hair bundle orientation is preserved. $\boldsymbol{D}-\boldsymbol{F}$ show the arrangement of $0 \mathrm{HC}$ hair bundle in the three groups. In $\boldsymbol{G}$, cochleogram data are shown (means \pm SEM). ${ }^{* * *} p<0.0001,{ }^{*} p<0.05$. Scale bar: $A-C, 20 \mu \mathrm{m} ; \boldsymbol{D}-\boldsymbol{F}, 8 \mu \mathrm{m}$.

\section{$\mathrm{CoQ}$ analog is protective against oxidative stress in the cochlea \\ $\mathrm{CoQ}_{9}$ and $\mathrm{CoQ}_{10}$ levels in the cochlea}

The quantification of quinone levels $\left(\mathrm{CoQ}_{9}\right.$ and $\left.\mathrm{CoQ}_{10}\right)$ was performed after the first trauma session (d 1) and after 10 consecutive days of noise exposure ( $\mathrm{d}$ 11). Moreover, we evaluated the CoQ levels $60 \mathrm{~d}$ after the first noise exposure. Figure $10 \mathrm{~A}$ shows the $\mathrm{CoQ}_{9}$ (left) and $\mathrm{CoQ}_{10}$ (right) levels in the cochlea. At day 1 , we observed a significant increase of $\mathrm{CoQ}_{9}$ in the Noise, Noise $_{\text {ter }}$, and $\mathrm{Ctrl}_{\text {ter }}$ groups with respect to Ctrl group; however, $\mathrm{CoQ}_{10}$ increased only in the Noise $\mathrm{Q}_{\text {ter }}$ and $\mathrm{CtrlQ}_{\text {ter }}$ groups. At day 11 , the $\mathrm{CoQ}_{9}$ and $\mathrm{CoQ}_{10}$ levels were increased significantly in $\mathrm{CtrlQ}_{\text {ter }}$ animals with respect to the other groups. In general, there was no difference in the levels of both $\mathrm{CoQ}_{9}$ and $\mathrm{CoQ}_{10}$ between the Noise and Noise $Q_{\text {ter }}$ groups. At day 60, there was a slight increase in $\mathrm{CoQ}_{9}$ and a decrease in $\mathrm{CoQ}_{10}$ levels in the Noise group. In Noise $Q_{\text {ter }}$ and $\mathrm{Ctrl}_{\text {ter }}$ groups, $\mathrm{CoQ}_{9}$ levels were significantly increased compared with the Ctrl group. In summary, rats treated with $\mathrm{Q}_{\text {ter }}\left(\mathrm{Noise}_{\mathrm{ter}}\right.$ and $\mathrm{Ctrl} \mathrm{Q}_{\text {ter }}$ ) show higher quinone levels than in the control (Ctrl) and noise-exposed (Noise) rats. These data suggest that the exogenous quinones can be used as ROS scavengers and exert a protective effect against oxidative stress.
$\mathrm{CoQ}_{9}$ and $\mathrm{CoQ}_{10}$ levels in the $A C s$

Figure $10 B$ shows the $\mathrm{CoQ}_{9}$ (left) and $\mathrm{CoQ}_{10}$ (right) levels in the ACs. The Noise group showed a significant reduction in $\mathrm{CoQ}_{9}$ and $\mathrm{CoQ}_{10}$ levels at both days 1 and 11 . Moreover, in NoiseQ $\mathrm{Q}_{\text {ter }}$ animals at days 1 and $11, \mathrm{CoQ}_{9}$ and $\mathrm{CoQ}_{10}$ levels were significantly higher compared with the Noise group. Significant differences were observed at day 60 for $\mathrm{CoQ}_{9}$ levels in NoiseQ $\mathrm{Q}_{\text {ter }}$ animals. $Q_{\text {ter }}$ administration succeeded in partially reversing the decreased $\mathrm{CoQ}_{9}$ and $\mathrm{CoQ}_{10}$ levels at days 1 and 11 . Considering that no differences were observed between Ctrl and CtrlQ ${ }_{\text {ter }}$, the beneficial contribution of $\mathrm{Q}_{\text {ter }}$ in the cortex could have been achieved through cochlear $\mathrm{Q}_{\text {ter }}$ protection that saved afferent fiber activity.

\section{Discussion}

This study provides evidence of the following: (1) AC modifications are associated with the cochlear oxidative damage induced by repeated noise exposure; (2) the reduction of the cochlear oxidative imbalance can be obtained by increasing CoQ activity through the administration of the water-soluble analog $\mathrm{Q}_{\text {ter }}$; (3) consequently, cortical neuronal morphology is partially restored. 

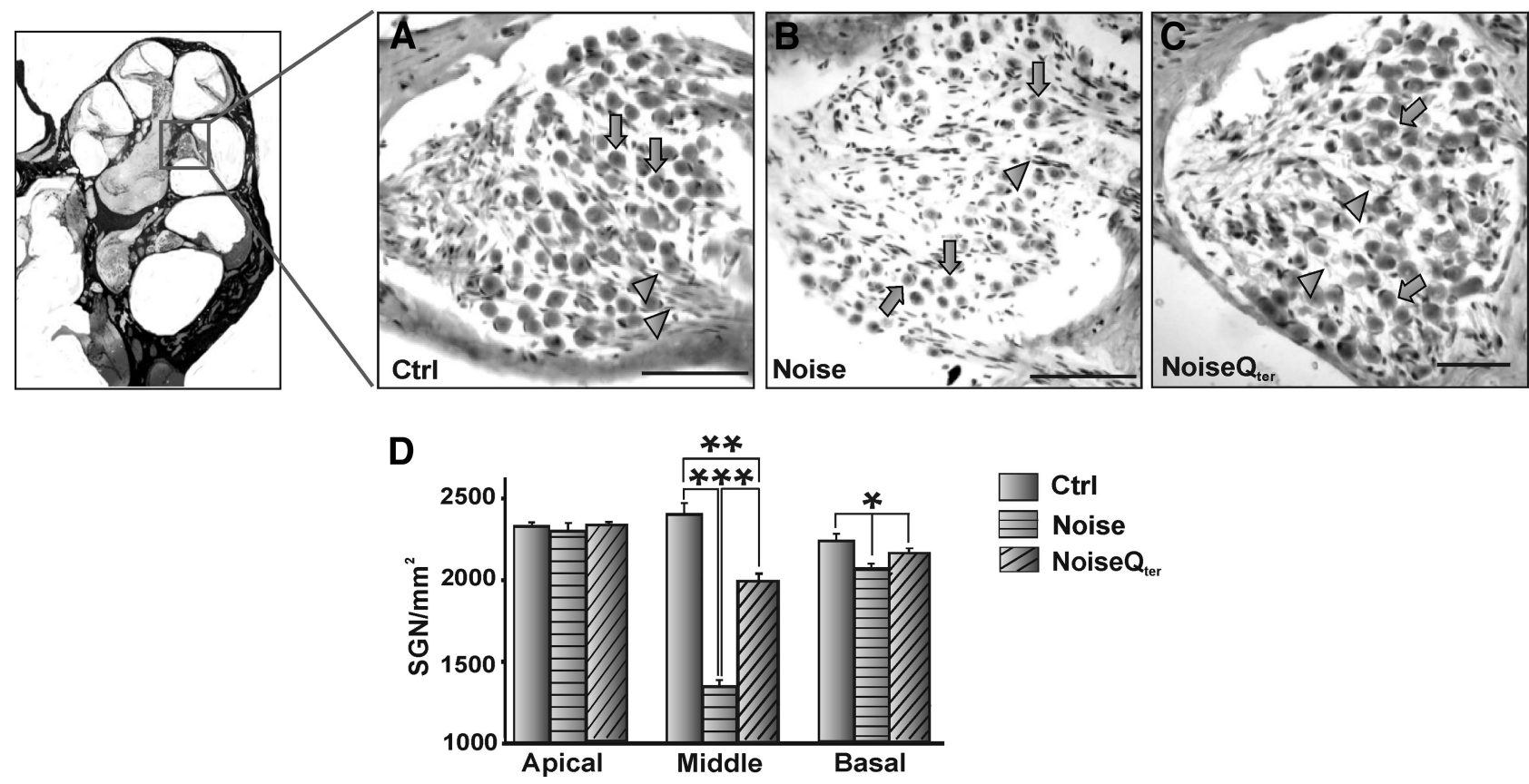

Figure 6. SGNs are protected by $Q_{\text {ter }}$ administration. $A$-C c show representative $S G N$ Niss stainings in the Ctrl, Noise, and Noise $Q_{\text {ter }}$ groups. Scale bar, $50 \mu \mathrm{m}$. The left shows a longitudinal section of the cochlea indicating (box) the middle turn area, severely damaged by noise. Arrows indicate SGN soma and arrowheads auditory fibers. $A$, The Rosenthal's canal is packed with SGNs and fascicles of auditory nerve fibers. $\boldsymbol{B}$, In the Noise group, $S G N$ soma appears smaller, their density is reduced, and fibers are thinner compared with controls. $C, Q_{\text {ter }}$ administration preserves $S G N s$ and fibers. D shows SGN viability presented as number of cells per square millimeters. ${ }^{*} p<0.05$, ${ }^{* *} p<0.001,{ }^{* * *} p<0.0001$, by one-way ANOVA.

\section{A}

A Camera lucida drawings

B Dendritic length

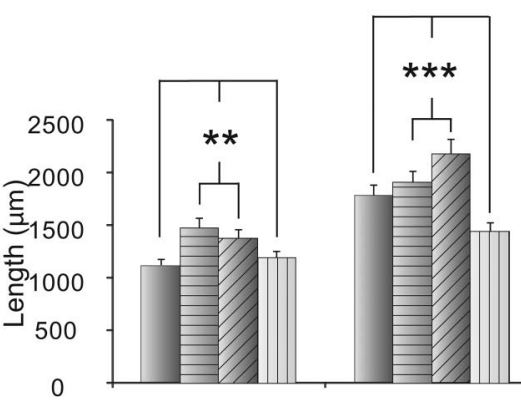

\section{Dendritic nodes}

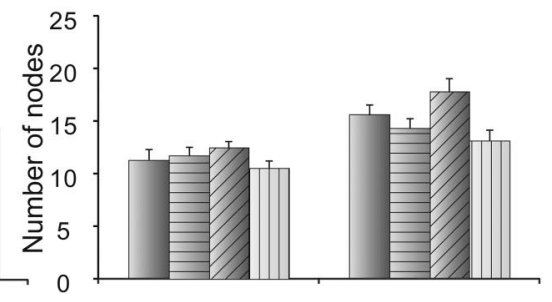

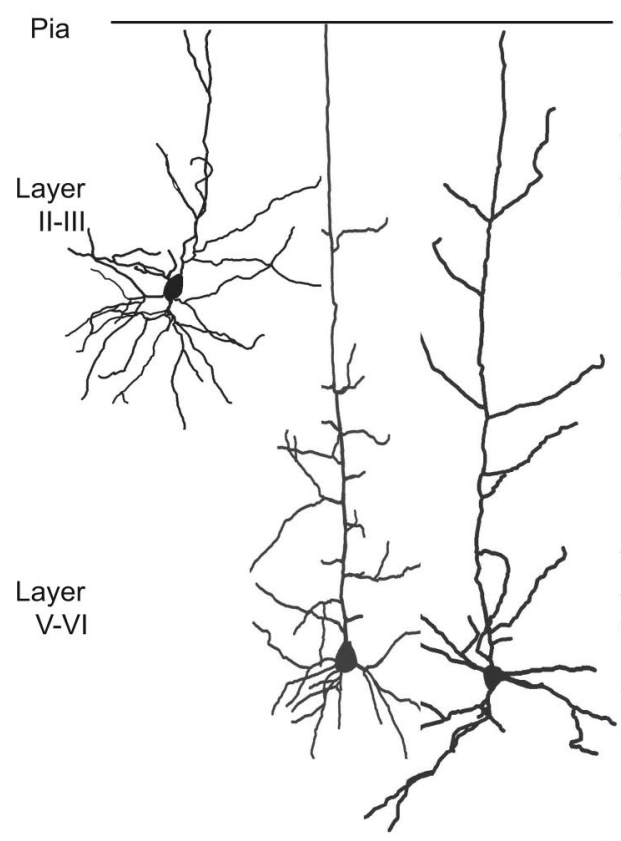

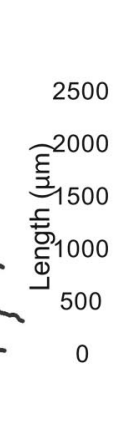

Ctrl
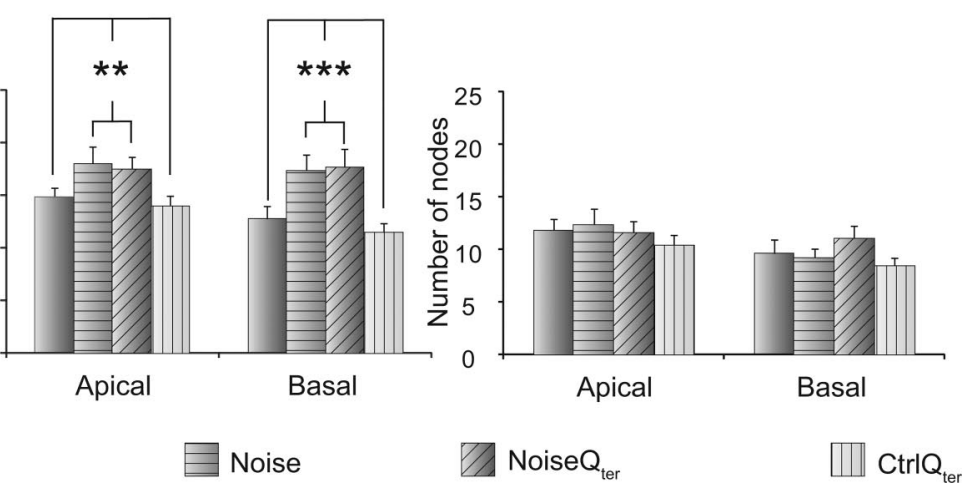

Figure 7. Effects of noise exposure and $Q_{\text {ter }}$ treatment on dendritic branching. $A$ shows camera lucida drawings of representative pyramidal neurons belonging to layers $I I-I I I$ and $V-V I$ of the ACs. $B$ and $C$ show the effects of noise exposure and $Q_{\text {ter }}$ treatment on dendritic branching of pyramidal neurons of II-III (above) and V-VI (below) layers. Histograms represent mean values of the length $(\boldsymbol{B})$ and nodes $(\boldsymbol{C})$ of apical and basal dendrites in the four experimental groups. Vertical bars indicate SEM. Noise $\times \mathrm{Q}_{\text {ter }}{ }^{* *} p<0.001$, ${ }^{* * *} p<0.0001$, significant effects of the noise factor in the absence of significant interactions from two-way ANOVAs.

Oxidative stress after repeated noise exposure

After noise exposure, there was a significant alteration in auditory function, OHC and SGN integrity, morphology of auditory pyramidal neurons, and cochlear redox status.
Alteration in auditory function, $\mathrm{OHC}$, and SGN integrity

As indicated by ABR recordings, thresholds increased across frequencies, and the P2 wave decreased in amplitude and increased in latency. The elevation of neural response thresholds at mid and 


\section{DENDRITIC SPINES OF LAYER II-III}

A

Terminal spine density

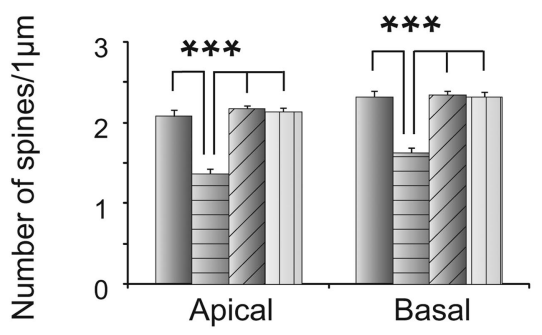

Total spine density

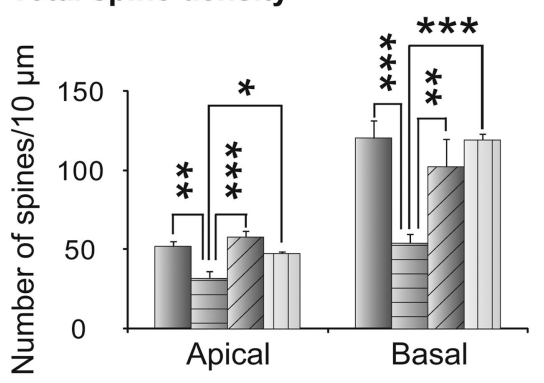

Maximal spine concentration

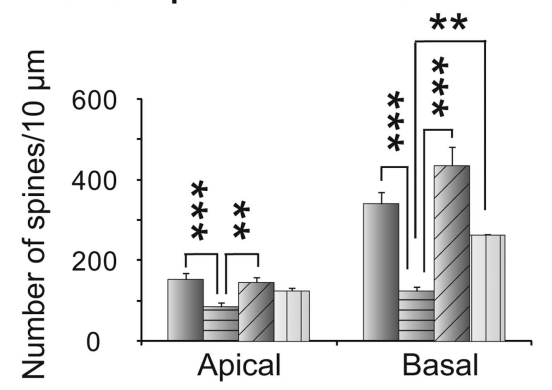

Maximal spine concentration position

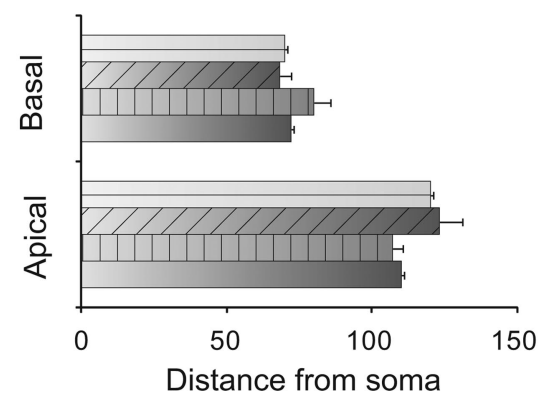

Ctrl
B
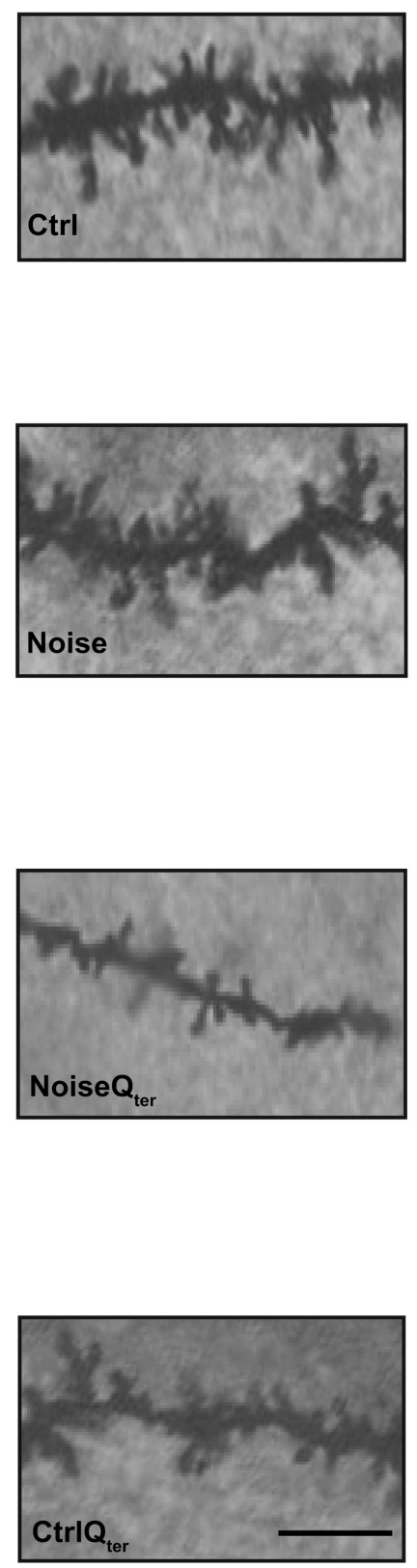

NoiseQ $Q_{\text {ter }}$ high frequencies indicated a perturbation of the cochlear amplifier and suggested an additional contribution of neural damage. Indeed, a pronounced decrease of OHCs (Fig. 5) and SGNs (Fig. 6) was found. However, OHC and SGN injuries were restricted mainly to the middle turn, whereas the threshold shifts were greater at frequencies above the noise band. More subtle changes in the HCs and other cochlear tissues, which we did not evaluate, may also have contributed to the noiseinduced threshold shifts and SGN loss (Wang and Ren, 2012; Zilberstein et al., 2012). Indeed, (Chen and Fechter, 2003), a correlation has been reported between NIHL and HC non-lethal impairments (Liberman and Dodds, 1984; Wang et al., 2002; Kujawa and Liberman, 2009; Lin et al., 2011).

\section{Alteration in morphology of auditory pyramidal neurons}

Increased dendritic length and decreased spine density in apical and basal arborizations of pyramidal neurons of layers II-III and V-VI in AC areas were observed. These changes were markedly similar regardless of layer and arborization, suggesting a common neuronal response to the acoustic trauma. Dendritic length and spine number are related to the degree of connectivity and complexity of cortical information processing providing the morphological substrate for both lesioninduced and context-dependent plastic events (McAllister, 2000). Most deafferentation studies have shown spine loss (Swann et al., 2000; McKinney, 2010). Namely, sensory deafness decreases spine density of auditory layer III pyramidal cells (Bose et al., 2010). Although reactive mechanisms may restore the lost synaptic complement, in most cases, spine density does not fully recover even months after deafferentation (Zuo et al., 2005). Indeed, we also show long-lasting alterations of auditory pyramidal neurons 60 days after acoustic trauma onset. Decreased spine density was paralleled by increased dendritic length. When the acoustic trauma does not shrink dendrites, spine loss may be explained by abnormal or excessive synaptic pruning attributable to enhanced synaptic competition. Hence, the spine loss may be caused by deafferentation and activity-dependent remodeling of neuronal connectivity. Thus, decreased spine density could represent a "trophic" response, whereby a diminished input cannot sustain a large number of excitatory connections. Alternatively, the deafferented neuron could compensate for the

Figure 8. Effects of noise exposure and $Q_{\text {ter }}$ treatment on dendritic spines of pyramidal neurons of layer II-III of ACS. $\boldsymbol{A}_{\text {, }}$ Histograms represent mean values of terminal density, total density, maximal concentration, and its position of apical and basal dendrites of the four experimental groups. Vertical bars indicate SEM. Noise $\times Q_{\text {ter }},{ }^{*} p<0.05,{ }^{* *} p<0.001,{ }^{* * *} p<$ 0.0001 , significant post hoc comparisons between groups in the presence of significant interactions from two-way ANOVAs $\boldsymbol{B}$, Photomicrographs visualizing the spines of apical dendritic segments of pyramidal neurons in the four experimental groups. Magnification, $1000 \times$. Scale bar, $25 \mu \mathrm{m}$. Note the loss of spines in the Noise group compared with the Ctrl group and the rescue effect of $Q_{\text {ter }}$ treatment in the Noise $Q_{\text {ter }}$ group in layers II-III. 
reduced drive by sensing global levels of activity and operating a homeostatic synaptic scaling (Turrigiano, 2008). In this way, decreased spine number could result in upregulated excitatory signaling and in preserved synaptic efficacies. A similar effect was observed in the visual cortex in which dark rearing results in decreased spine density and augmented excitatory postsynaptic events (Desai et al., 2002).

\section{Cochlear redox status}

The oxidative status after noise exposure and the CoQ role were shown by the enhanced superoxide production and lipid peroxidation in HCs and SGNs. Indeed, decreased CoQ content can lead to the inactivation of respiratory chain enzymes (Matthews et al., 1998), inducing a vicious cycle in which the impaired enzymes enhance ROS production (ForsmarkAndrée et al., 1997). Our AC morphological alterations as well could be consistent with data reporting spine loss either after the induction of oxidative stress (Avila-Costa et al., 2001; Zaja-Milatovic et al., 2008) or with oxidative damage after noise exposure (Cheng et al., 2011) or visual sensory deprivation (Hernandes et al., 2010). However, the decreased cortical $\mathrm{CoQ}_{9}$ and $\mathrm{CoQ}_{10}$ levels at days 1 and 11 in the Noise group are, more likely, a consequence of changes in metabolic activity attributable to afferent inactivity and upward spread of cochlear damage (Gröschel et al., 2010). In fact, cochlear integrity and afferent regulation is crucial for neuronal maintenance and survival in auditory brainstem circuitry and cortical areas. Afferent deprivation may induce depletion of cellular energy stores (Minami et al., 2007), a decrease in glucose metabolism (Smittkamp et al., 2005), lipid peroxidation, and calcium homeostasis alterations that are critical for ROS elevation (Nicholas and Hyson, 2006). Thus, our data support studies showing a metabolic downregulation after deafferentation attributable to the removal of the cochlea (Ahn et al., 2004; Nicholas and Hyson, 2006). Considering that CoQ is a factor involved in mitochondrial processes, as well as a powerful antioxidant (Lenaz, 2012), the decrease of $\mathrm{CoQ}_{9}$ and $\mathrm{CoQ}_{10}$ observed at days 1 and 11 in the AC could be ascribed to deafferentation-induced metabolic alterations, leading to cortical insult.

\section{Reduction of cochlear oxidative imbalance}

Systemic $Q_{\text {ter }}$ administration reduced oxidative stress in the cochlea and strongly decreased the hearing loss

The reduced oxidative stress is consistent with the increased levels of the endogenous quinones after the administration of $\mathrm{Q}_{\mathrm{ter}}$. Specifically, after $\mathrm{Q}_{\text {ter }}$ administration, the levels of $\mathrm{CoQ}_{9}$ in-

A

Ctrl

\section{DENDRITIC SPINES OF LAYER V-VI}

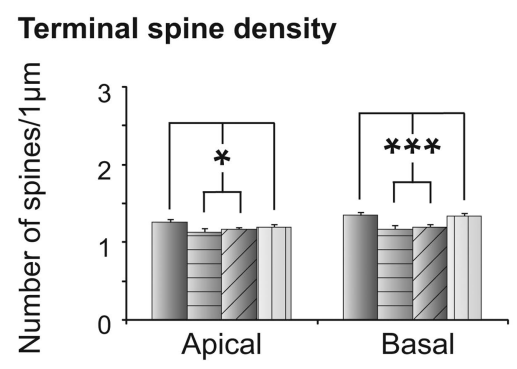

\section{B}
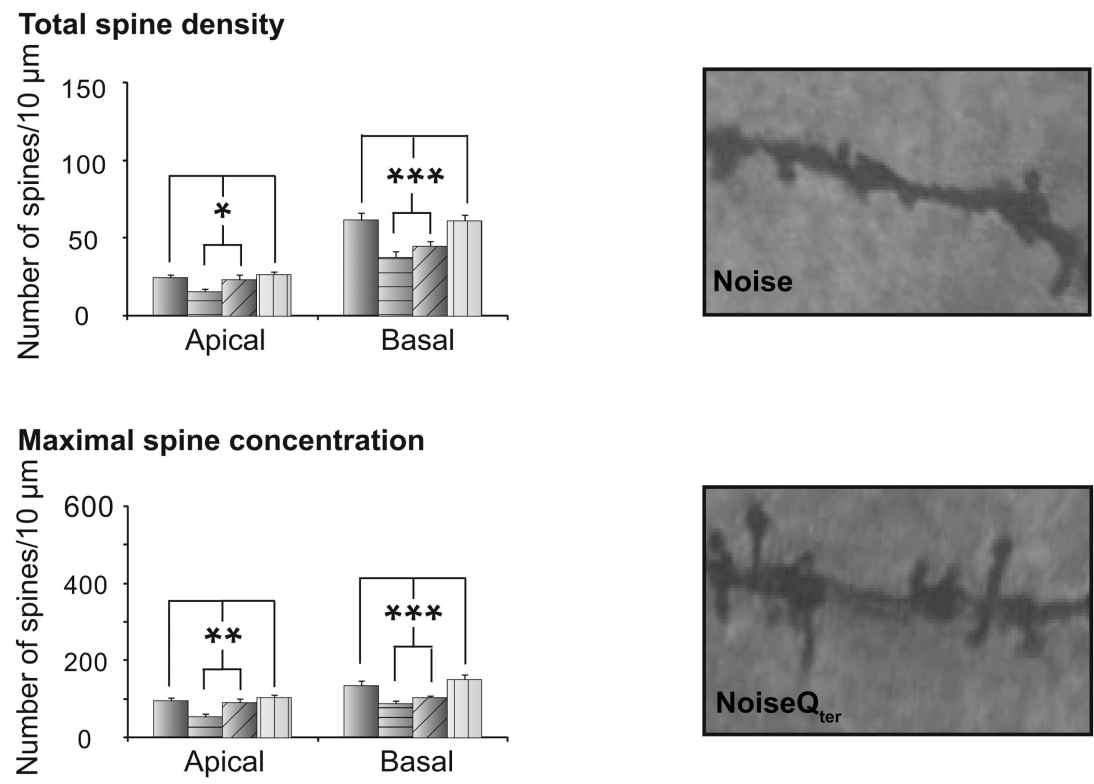

Maximal spine concentration positon

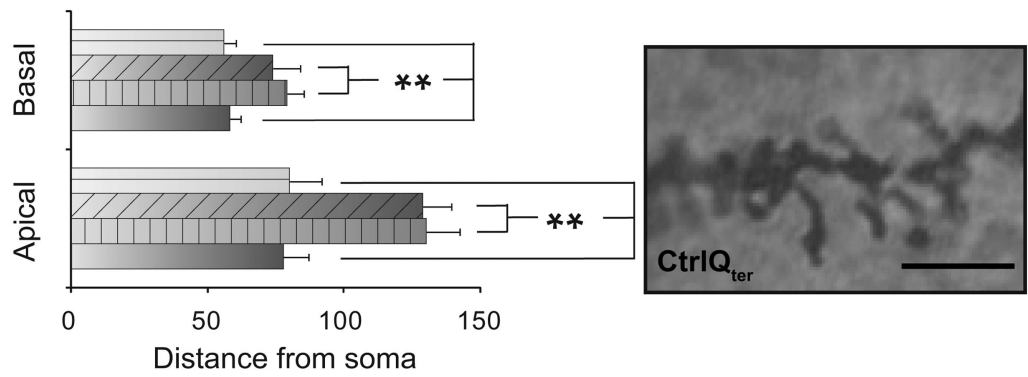

Noise

Noise $Q_{\text {ter }}$

CtrlQ

Figure 9. Effects of noise exposure and $\mathrm{Q}_{\text {ter }}$ treatment on dendritic spines of pyramidal neurons of layers $\mathrm{V}-\mathrm{VI}$ of $\mathrm{ACs}$. $\boldsymbol{A}$, Histograms represent mean values of terminal density, total density, maximal concentration, and its position of apical and basal dendrites of the four experimental groups. Vertical bars indicate SEM. Noise $\times Q_{\text {ter }}{ }^{*} p<0.05,{ }^{* *} p<0.001,{ }^{* * *} p<0.0001$, significant effects of the noise factor in the absence of significant interactions from two-way ANOVAs. $\boldsymbol{B}$, Photomicrographs visualizing the spines of apical dendritic segments of pyramidal neurons in the four experimental groups. Magnification, $1000 \times$. Scale bar, $25 \mu \mathrm{m}$. Note the loss of spines in the Noise group compared with the $\mathrm{Ctrl}$ group maintained also in the presence of $\mathrm{Q}_{\mathrm{ter}}$ treatment in the Noise $\mathrm{Q}_{\text {ter }}$ group. creased in the cochleae of intact animals, indicating that the exogenous quinone can exert a protective effect on animal tissue. In the Noise $Q_{\text {ter }}$ group, $\mathrm{CoQ}_{9}$ levels were decreased at the end of treatment compared with the $C \operatorname{ctrl} \mathrm{Q}_{\text {ter }}$ group, indicating that the exogenous quinone was used as scavenger during noise exposure to reduce the oxidative imbalance. This scavenging would thus prevent the morphological and functional cochlear damage, the 
A

$\mathrm{CoQ}_{9}$
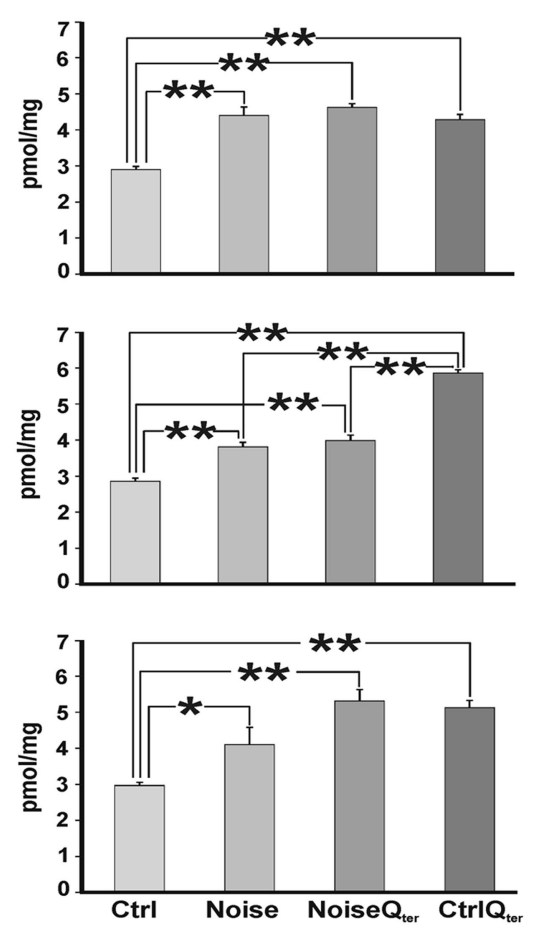

COCHLEA Day 1

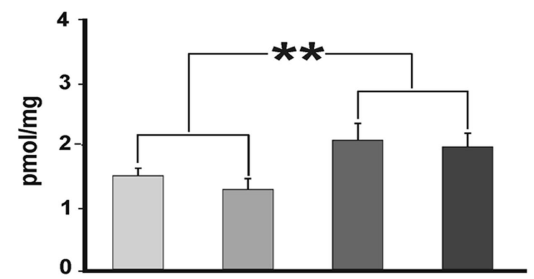

Day 11

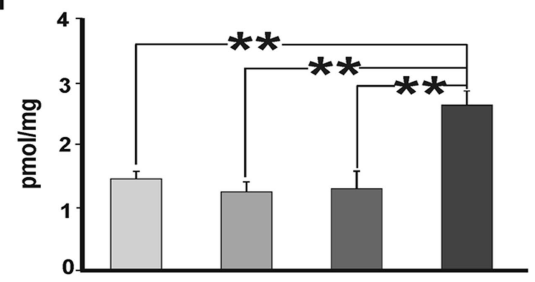

Day 60

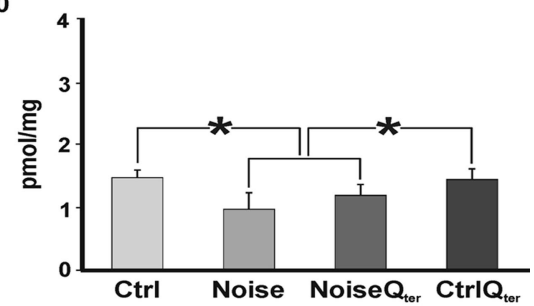

B
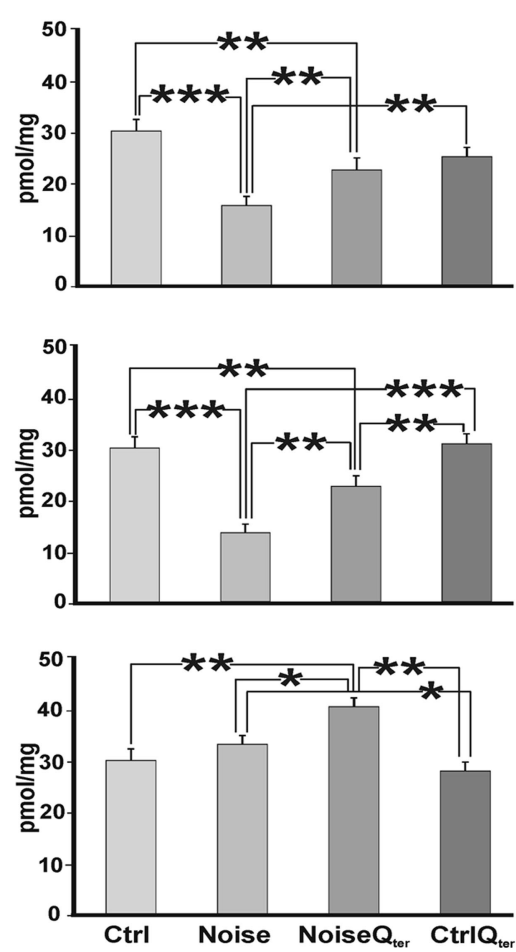

AUDITORY CORTEX

Day 1

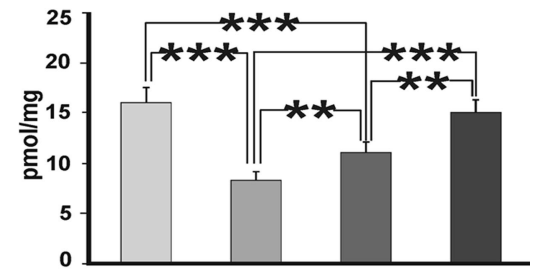

Day 11

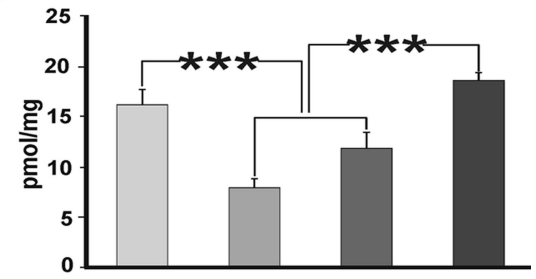

Day 60

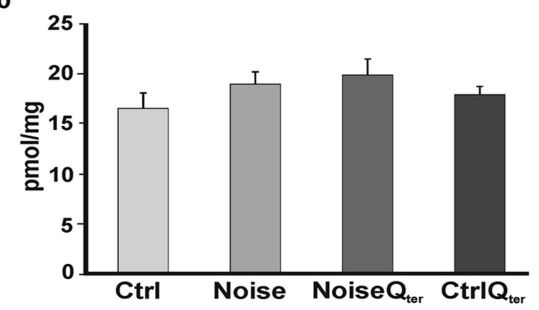

Figure 10. $Q_{\text {ter }}$ increases $\mathrm{CO}_{9}$ and $\mathrm{CO}_{10}$ levels in the cochlea. Levels of $\mathrm{CO}_{9}$ and $\mathrm{CO}_{10}$ are measured in the cochlea and $\mathrm{AC}$. The amount of $\mathrm{COQ}_{9}$ (left) and $\mathrm{COQ}_{10}$ (right) in the cochlea $(\boldsymbol{A})$ and $\mathrm{AC}(\boldsymbol{B})$ is expressed as picomoles of $\mathrm{COQ}$ normalized to tissue wet weight at different time points $(1,11$, and $60 \mathrm{~d}$ after noise exposure onset) in all experimental groups. In the cochlea, rats treated with $\mathrm{Q}_{\text {ter }}\left(\mathrm{Noise}_{\text {ter }}\right.$ and $\left.\mathrm{Crrl}_{\mathrm{ter}}\right)$ show higher quinone levels than in the $\mathrm{Ctrl}$ and Noise groups. In the AC, no differences are observed between $\mathrm{Ctrl}$ and $\mathrm{Ctrl} \mathrm{Q}_{\text {ter }}$ groups. Noise $\times 0_{\text {ter }}{ }^{*} p<0.05,{ }^{* *} p<0.001,{ }^{* * *} p<0.0001$, significant post hoc comparisons between groups from two-way ANOVAs.

deafferentation, and the upward spread of the cochlear damage. The scavenging activity of the exogenous CoQ is further supported by the higher $\mathrm{CoQ}_{9}$ levels in Noise $Q_{\text {ter }}$ group with respect to the Noise group when the noise exposure had ceased $\left(\mathrm{CoQ}_{9}\right.$ increase in $\mathrm{Noise}_{\text {ter }}$ group to $\mathrm{CtrlQ}_{\text {ter }}$ level at d 60). Last, the increase of $\mathrm{CoQ}_{9}$ in the Noise group compared with the Ctrl group may be explained by either compensatory mechanisms allowing increased biosynthesis of quinones (Ibrahim et al., 2000; Bhagavan and Chopra, 2006) and/or their recruitment from circulating lipoproteins in the attempt to maintain the cochlear CoQ level.

Systemic $Q_{\text {ter }}$ administration selectively affects morphology of cortical pyramidal neurons

At odds with cochlea, no accumulation of quinone occurred in the cortex after $\mathrm{Q}_{\text {ter }}$ treatment given that, in the $\mathrm{CtrlQ}_{\text {ter }}$ group, $\mathrm{CoQ}{ }_{9}$ and $\mathrm{CoQ}_{10}$ values paralleled $\mathrm{Ctrl}$ group levels. These data suggest that CoQ levels are tightly regulated and saturated in membranes in the cortex (Matthews et al., 1998). However, it is more likely that the protective effect of $\mathrm{Q}_{\text {ter }}$ observed in the AC is a consequence of $Q_{\text {ter }}$ effect on the cochlea. Thus, the rescued deafferentation upstream of the auditory pathway reestablished the physiological neuronal activity and restored AC metabolism as indicated by $\mathrm{CoQ}_{9}$ and $\mathrm{CoQ}_{10}$ levels.

Together, $\mathrm{Q}_{\text {ter }}$ treatment was able to protect against NIHL, preserve $\mathrm{OHC}$ and SGN integrity, and prevent the impairment of the pyramidal dendritic pattern in layers II-III. Interestingly, $\mathrm{Q}_{\text {ter }}$ did not restore dendritic morphology of pyramidal neurons of layers V-VI. The different response of the two cortical layers may be related to the laminar organization of the afferent and efferent fibers. The AC and other sensory cortices show dense and well-developed layers II-III mainly involved in corticocortical circuits and relatively cell-sparse and reduced layers V-VI involved in cortico-subcortical circuits (Linden and Schreiner, 2003; Paxinos and Watson, 2007). Thus, it appears justified that AC neuronal rearrangement mainly engages the corticocortical circuits and that the plastic changes of the layers II-III are the substrate for cortical plasticity. The marked plasticity of layers II-III has been reported in the $\mathrm{AC}$ in response to acoustic enrichment (Bose et al., 2010) and in other sensory cortices after different stimulations, such as administration of psychoactive drugs (Robinson and Kolb, 1999; De Bartolo et al., 2009) or ex- 
posure to environmental enrichment (Gelfo et al., 2009). Environmental enrichment affects the morphology of layer III, but not layer $\mathrm{V}$, pyramidal neurons of parietal cortex (Johansson and Belichenko, 2002; Gelfo et al., 2009).

In conclusion, our findings show that cochlear and cortical damage is ameliorated by the administration of $\mathrm{CoQ}_{10}$, supporting the notion that NIHL is strongly related to altered equilibrium processes and loss of energetic capacity to meet an oxidative challenge.

\section{References}

Ahn SH, Oh SH, Lee JS, Jeong JM, Lim D, Lee DS, Kim CS (2004) Changes of 2-deoxiglucose uptake in the rat auditory pathway after bilateral ablation of the cochlea. Hear Res 196:33-38. CrossRef Medline

Alvarado JC, Fuentes-Santamaría V, Jareño-Flores T, Blanco JL, Juiz JM (2012) Normal variations in the morphology of auditory brainstem response (ABR) waveforms: a study in Wistar rats. Neurosci Res 73: 302-311. CrossRef Medline

Avila-Costa MR, Colín-Barenque L, Fortoul TI, Machado-Salas JP, EspinosaVillanueva J, Rugerio-Vargas C, Borgonio G, Dorado C, Rivas-Arancibia S (2001) Motor impairments in an oxidative stress model and its correlation with cytological changes on rat striatum and prefrontal cortex. Int J Neurosci 108:193-200. Medline

Bergamini C, Moruzzi N, Sblendido A, Lenaz G, Fato R (2012) A water soluble $\mathrm{CoQ}(10)$ formulation improves intracellular distribution and promotes mitochondrial respiration in cultured cells. PLoS One 7:e33712. CrossRef Medline

Bhagavan HN, Chopra RK (2006) Coenzyme Q10: absorption, tissue uptake, metabolism and pharmacokinetics. Free Radic Res 40:445-453. CrossRef Medline

Boettcher FA, Mills JH, Swerdloff JL, Holley BL (1996) Auditory evoked potentials in aged gerbils: responses elicited by noises separated by a silent gap. Hear Res 102:167-178. Medline

Bose M, Muñoz-Llancao P, Roychowdhury S, Nichols JA, Jakkamsetti V, Porter B, Byrapureddy R, Salgado H, Kilgard MP, Aboitiz F, DagninoSubiabre A, Atzori M (2010) Effect of the environment on the dendritic morphology of the rat auditory cortex. Synapse 64:97-110. CrossRef Medline

Chen GD, Fechter LD (2003) The relationship between noise-induced hearing loss and hair cell loss in rats. Hear Res 177:81-90. CrossRef Medline

Cheng L, Wang SH, Chen QC, Liao XM (2011) Moderate noise induced cognition impairment of mice and its underlying mechanisms. Physiol Behav 104:981-988. CrossRef Medline

Church MW, Hotra JW, Holmes PA, Anumba JI, Jackson DA, Adams BR (2012) Auditory brainstem response (ABR) abnormalities across the life span of rats prenatally exposed to alcohol. Alcohol Clin Exp Res 36:83-96. CrossRef Medline

De Bartolo P, Gelfo F, Mandolesi L, Foti F, Cutuli D, Petrosini L (2009) Effects of chronic donepezil treatment and cholinergic deafferentation on parietal pyramidal neuron morphology. J Alzheimers Dis 17:177-191. CrossRef Medline

DeFelipe J, Fariñas I (1992) The pyramidal neuron of the cerebral cortex: morphological and chemical characteristics of the synaptic inputs. Prog Neurobiol 39:563-607. CrossRef Medline

Desai NS, Cudmore RH, Nelson SB, Turrigiano GG (2002) Critical periods for experience-dependent synaptic scaling in visual cortex. Nat Neurosci 5:783-789. CrossRef Medline

Fetoni AR, Piacentini R, Fiorita A, Paludetti G, Troiani D (2009) Watersoluble Coenzyme Q10 formulation (Q-ter) promotes outer hair cell survival in a guinea pig model of noise induced hearing loss (NIHL). Brain Res 1257:108-116. CrossRef Medline

Fetoni AR, Mancuso C, Eramo SL, Ralli M, Piacentini R, Barone E, Paludetti G, Troiani D (2010) In vivo protective effect of ferulic acid against noise-induced hearing loss in the guinea-pig. Neuroscience 169:15751588. CrossRef Medline

Fetoni AR, Troiani D, Eramo SL, Rolesi R, Paludetti Troiani G (2012) Efficacy of different routes of administration for Coenzyme Q10 formulation in noise-induced hearing loss: systemic versus transtympanic modality. Acta Otolaryngol 132:391-399. CrossRef Medline

Forsmark-Andrée P, Lee CP, Dallner G, Ernster L (1997) Lipid peroxidation and changes in the ubiquinone content and the respiratory chain enzymes of submitochondrial particles. Free Radic Biol Med 22:391-400. CrossRef Medline

Gelfo F, De Bartolo P, Giovine A, Petrosini L, Leggio MG (2009) Layer and regional effects of environmental enrichment on the pyramidal neuron morphology of the rat. Neurobiol Learn Mem 91:353-365. CrossRef Medline

Gibb R, Kolb B (1998) A method for vibratome sectioning of Golgi-Cox stained whole rat brain. J Neurosci Methods 79:1-4. CrossRef Medline

Glaser EM, Van der Loos H (1981) Analysis of thick brain sections by obverse-reverse computer microscopy: application of a new, high clarity Golgi-Nissl stain. J Neurosci Methods 4:117-125. CrossRef Medline

Gröschel M, Götze R, Ernst A, Basta D (2010) Differential impact of temporary and permanent noise-induced hearing loss on neuronal cell density in the mouse central auditory pathway. J Neurotrauma 27: 1499-1507. CrossRef Medline

Henderson D, Bielefeld EC, Harris KC, Hu BH (2006) The role of oxidative stress in noise-induced hearing loss. Ear Hear 27:1-19. CrossRef Medline

Hernandes MS, Britto LR, Real CC, Martins DO, Lopes LR (2010) Reactive oxygen species and the structural remodeling of the visual system after ocular enucleation. Neuroscience 170:1249-1260. CrossRef Medline

Hidaka T, Fujii K, Funahashi I, Fukutomi N, Hosoe K (2008) Safety assessment of coenzyme Q10 (CoQ10). Biofactors 32:199-208. Medline

Hu BH, Henderson D (1997) Changes in F-actin labeling in the outer hair cell and the Deiter's cell in the chinchilla cochlea following noise exposure. Hear Res 110:209-218. Medline

Ibrahim WH, Bhagavan HN, Chopra RK, Chow CK (2000) Dietary coenzyme Q10 and vitamin E alter the status of these compounds in rat tissues and mitochondria. J Nutr 130:2343-2348. Medline

Johansson BB, Belichenko PV (2002) Neuronal plasticity and dendritic spines: effect of environmental enrichment on intact and postischemic rat brain. J Cereb Blood Flow Metab 22:89-96. Medline

Kotak VC, Breithaupt AD, Sanes DH (2007) Developmental hearing loss eliminates long-term potentiation in the auditory cortex. Proc Natl Acad Sci U S A 104:3550-3555. CrossRef Medline

Kujawa SG, Liberman MC (2009) Adding insult to injury: cochlear nerve degeneration after "temporary" noise-induced hearing loss. J Neurosci 29:14077-14085. CrossRef Medline

Lenaz G (2012) Mitochondria and reactive oxygen species. Which role in physiology and pathology? Adv Exp Med Biol 942:93-136. CrossRef Medline

Lenaz G, Fato R, Formiggini G, Genova ML (2007) The role of Coenzyme Q in mitochondrial electron transport. Mitochondrion S7:S8-S33. CrossRef Medline

Le Prell CG, Yamashita D, Minami SB, Yamasoba T, Miller JM (2007) Mechanisms of noise-induced hearing loss indicate multiple methods of prevention. Hear Res 226:22-43. CrossRef Medline

Liberman MC, Dodds LW (1984) Single-neuron labeling and chronic cochlea pathology. III. Stereocilia damage and alterations of threshold tuning curves. Hear Res 16:55-74. CrossRef Medline

Lin HW, Furman AC, Kujawa SG, Liberman MC (2011) Primary neural degeneration in the Guinea pig cochlea after reversible noise-induced threshold shift. J Assoc Res Otolaryngol 12:605-616. CrossRef Medline

Linden JF, Schreiner CE (2003) Columnar transformations in auditory cortex? A comparison to visual and somatosensory cortices. Cereb Cortex 13:83-89. CrossRef Medline

Matthews RT, Yang L, Browne S, Baik M, Beal MF (1998) Coenzyme Q10 administration increases brain mitochondrial concentrations and exerts neuroprotective effects. Proc Natl Acad Sci U S A 95:8892-8897. CrossRef Medline

McAllister AK (2000) Cellular and molecular mechanisms of dendrite growth. Cereb Cortex 10:963-973. CrossRef Medline

McKinney RA (2010) Excitatory amino acid involvement in dendritic spine formation, maintenance and remodelling. J Physiol 588:107-116. CrossRef Medline

Mills JH, Adkins WY, Gilbert RM (1981) Temporary threshold shifts produced by wideband noise. J Acoust Soc Am 70:390-396. CrossRef Medline

Minami SB, Yamashita D, Ogawa K, Schacht J, Miller JM (2007) Creatine and tempol attenuate noise-induced hearing loss. Brain Res 1148:83-89. CrossRef Medline

Nicholas AH, Hyson RL (2006) Afferent regulation of oxidative stress in the chick cochlear nucleus. Neuroscience 140:1359-1368. CrossRef Medline 
Ohinata Y, Miller JM, Altschuler RA, Schacht J (2000) Intense noise induces formation of vasoactive lipid peroxidation products in the cochlea. Brain Res 878:163-173. CrossRef Medline

Paxinos G, Watson C (2007) The rat brain in stereotaxic coordinates. Amsterdam: Academic Elsevier.

Pienkowski M, Eggermont JJ (2011) Cortical tonotopic map plasticity and behavior. Neurosci Biobehav Rev 35:2117-2128. CrossRef Medline

Pienkowski M, Munguia R, Eggermont JJ (2011) Passive exposure of adult cats to bandlimited tone pip ensembles or noise leads to long-term response suppression in auditory cortex. Hear Res 277:117-126. CrossRef Medline

Poirrier AL, Pincemail J, Van Den Ackerveken P, Lefebvre PP, Malgrange B (2010) Oxidative stress in the cochlea: an update. Curr Med Chem 17: 3591-3604. CrossRef Medline

Robinson TE, Kolb B (1999) Alterations in the morphology of dendrites and dendritic spines in the nucleus accumbens and prefrontal cortex following repeated treatment with amphetamine or cocaine. Eur J Neurosci 11:1598-1604. CrossRef Medline

Scholl B, Wehr M (2008) Disruption of balanced cortical excitation and inhibition by acoustic trauma. J Neurophysiol 100:646-656. CrossRef Medline

Sholl DA (1956) The organization of the cerebral cortex. London: Methuen.

Smittkamp SE, Girod DA, Durham D (2005) Role of cochlear integrity in cochlear nucleus glucose metabolism and neuron number after cochlea removal in aging broiler chickens. Hear Res 204:48-59. CrossRef Medline

Stolzberg D, Chen GD, Allman BL, Salvi RJ (2011) Salicylate-induced peripheral auditory changes and tonotopic reorganization of auditory cortex. Neuroscience 180:157-164. CrossRef Medline

Swann JW, Al-Noori S, Jiang M, Lee CL (2000) Spine loss and other dendritic abnormalities in epilepsy. Hippocampus 10:617-625. CrossRef Medline

Syka J (2002) Plastic changes in the central auditory system after hearing loss, restoration of function, and during learning. Physiol Rev 82:601636. CrossRef Medline

Takada M, Ikenoya S, Yuzuriha T, Katayama K (1984) Simultaneous deter- mination of reduced and oxidized ubiquinones. Methods Ezymol 105: 147-155. CrossRef Medline

Takemura K, Komeda M, Yagi M, Himeno C, Izumikawa M, Doi T, Kuriyama H, Miller JM, Yamashita T (2004) Direct inner ear infusion of dexamethasone attenuates noise-induced trauma in guinea pig. Hear Res 196: 58-68. CrossRef Medline

Turrigiano GG (2008) The self-tuning neuron: synaptic scaling of excitatory synapses. Cell 135:422-435. CrossRef Medline

Viberg A, Canlon B (2004) The guide to plotting a cochleogram. Hear Res 197:1-10. CrossRef Medline

Wang H, Brozoski TJ, Caspary DM (2011) Inhibitory neurotransmission in animal models of tinnitus: maladaptive plasticity. Hear Res 279: 111-117. CrossRef Medline

Wang Y, Ren C (2012) Effects of repeated "benign" noise exposures in young CBA mice: shedding light on age-related hearing loss. J Assoc Res Otolaryngol 13:505-515. CrossRef Medline

Wang Y, Hirose K, Liberman MC (2002) Dynamics of noise-induced cellular injury and repair in the mouse cochlea. J Assoc Res Otolaryngol 3:248 268. CrossRef Medline

Xu J, Seo AY, Vorobyeva DA, Carter CS, Anton SD, Lezza AM, Leeuwenburgh C (2010) Beneficial effects of a Q-ter based nutritional mixture on functional performance, mitochondrial function, and oxidative stress in rats. PLoS One 5:e10572. CrossRef Medline

Yamashita D, Jiang HY, Schacht J, Miller JM (2004) Delayed production of free radicals following noise exposure. Brain Res 1019:201-209. CrossRef Medline

Zaja-Milatovic S, Gupta RC, Aschner M, Montine TJ, Milatovic D (2008) Pharmacologic suppression of oxidative damage and dendritic degeneration following kainic acid-induced excitotoxicity in mouse cerebrum. Neurotoxicology 29:621-627. CrossRef Medline

Zilberstein Y, Liberman MC, Corfas G (2012) Inner hair cells are not required for survival of spiral ganglion neurons in the adult cochlea. J Neurosci 32:405-410. CrossRef Medline

Zuo Y, Lin A, Chang P, Gan WB (2005) Development of long-term dendritic spine stability in diverse regions of cerebral cortex. Neuron 46:181-189. CrossRef Medline 